\title{
The Propagation of Mountain Waves into the Stratosphere: Quantitative Evaluation of Three-Dimensional Simulations
}

\author{
MARTin LeutBecher* AND Hans VOLKerT \\ Institut für Physik der Atmosphäre, Deutsches Zentrum für Luft- und Raumfahrt, Oberpfaffenhofen, Germany
}

(Manuscript received 9 March 1999, in final form 17 November 1999)

ABSTRACT

\begin{abstract}
On 6 January 1992 measurements of a mountain wave with significant amplitude were taken over the southern tip of Greenland during an ER-2 flight at an altitude of about $20 \mathrm{~km}$. This work focuses on 3D numerical simulations of the wave generation and its propagation into the stratosphere during this event. The sensitivity of the simulated mountain wave to surface friction and horizontal resolution is explored. A nonhydrostatic model is used for experiments with horizontal resolutions of 12,4 , and $1.3 \mathrm{~km}$.

In all simulations the flow over the southern tip of Greenland generates a mountain wave, which propagates into the stratosphere. Changes of surface friction and horizontal resolution affect mostly the amplitude of the mountain wave. Increasing surface friction on the slopes reduces the amplitude of the excited orographic gravity wave. Horizontal diffusion required for numerical stability attenuates gravity waves during their propagation into the stratosphere. Increasing the horizontal resolution permits a smaller diffusion and thereby results in larger stratospheric wave amplitudes.

The experiment with increased surface friction at $1.3-\mathrm{km}$ horizontal resolution shows the best agreement with the observational data of the wave in the stratosphere. The differences between the simulated and measured amplitudes of vertical displacement and temperature anomaly are less than about $20 \%$. The disparity in vertical velocity is larger; downward velocities were observed up to $4.8 \mathrm{~m} \mathrm{~s}^{-1}$ and simulated up to $2.7 \mathrm{~m} \mathrm{~s}^{-1}$. In the experiments with lower surface friction at 4-km resolution, the accuracy regarding the amplitude of vertical displacement and temperature anomalies is similar, but the simulated maximum downdraft is even weaker. The other experiments with increased surface friction at 4-km resolution and normal friction at $12-\mathrm{km}$ resolution significantly underestimate the wave amplitude. The results of the experiments suggest that the generation of orographic gravity waves and their propagation into the stratosphere can be simulated in three dimensions in a realistic manner provided that the magnitude of the parameterized surface friction is in a realistic range and the horizontal resolution is sufficient.
\end{abstract}

\section{Introduction}

Large amplitude gravity waves are abundant in the stratosphere. Flow over orography is thought to be a major source of these gravity waves (Nastrom and Fritts 1992). The vertical propagation of orographically generated gravity waves into the stratosphere is generally possible unless critical levels are present or trapping occurs. Trapping affects the nonhydrostatic gravity waves that have a horizontal wavelength of about $10-$ $20 \mathrm{~km}$ (Shutts 1992). The propagation of the entire gravity wave spectrum is prevented at a level where the ambient wind vanishes. When the wind vector turns with

* Current affiliation: ECMWF, Reading, United Kingdom

Corresponding author address: Martin Leutbecher, European Centre for Medium-Range Weather Forecasts, Shinfield Park, Reading RG2 9AX, United Kingdom.

E-mail: M.Leutbecher@ecmwf.int altitude, the vertical propagation is limited to the part of the spectrum that does not encounter a level where the horizontal wave vector is normal to the ambient flow (Shutts 1998).

Gravity waves are known to influence stratospheric dynamics. The dissipation of orographic gravity waves greatly affects the atmospheric momentum budget. This process needs to be parameterized in global circulation models, which either do not sufficiently resolve these waves or do not resolve them at all (Palmer et al. 1986; McFarlane 1987). The distribution of trace constituents in the stratosphere is affected by the mixing induced by breaking gravity waves (Lilly and Lester 1974). This mixing can be relevant as the stratosphere is known to be a region of the atmosphere where the vertical exchange of matter is very low.

Gravity waves induce mesoscale temperature anomalies. Thereby they can trigger microphysical processes in the stratosphere. Cold anomalies in the stratosphere can cause supersaturation with respect to water or other trace constituents, which in turn leads to the formation 
of clouds. Potter and Holton (1995) propose a dehydration mechanism of the tropical lower stratosphere that involves cloud formation in the stratosphere due to gravity waves caused by convection. The study of Carslaw et al. (1998a) suggests that polar stratospheric clouds (PSCs) induced by mountain waves on the mesoscale may contribute significantly to the ozone depletion in the Arctic stratosphere. PSCs induced by mountain waves have been identified and characterized by remote sensing (Carslaw et al. 1998b) and in situ measurements (Schreiner et al. 1999).

Starting from the early work by Lyra (1943) and Queney (1947) linear theory has been central to the understanding of orographic gravity waves up to present. The linearization well approximates small amplitude waves. When the wave amplitude is larger, the results from linear theory are often qualitatively similar to finiteamplitude solutions, but quantitatively large errors can occur (Durran 1992). As the amplitude of gravity waves increases with altitude with the inverse square root of density and density decreases vertically by an order of magnitude about every $15 \mathrm{~km}$, large amplitude gravity waves and wave breaking are commonplace in the stratosphere. Therefore, nonlinear numerical simulations are required to study orographic gravity waves even over orography of moderate height.

Most of the previous numerical experiments of orographic flows with domains extending well into the stratosphere simulated flows in two-dimensional slices (e.g., Bacmeister and Schoeberl 1989; Durran 1995). Unless the orography is almost two-dimensional this is a severe restriction, as several important processes cannot be modelled in two-dimensional settings. Three-dimensional dispersion spreads the gravity wave energy acting to reduce the amplitude with increasing height (Smith 1980). This counteracts the growth of wave amplitude resulting from the decreasing density. High isolated orography diverts the low-level flow horizontally whereas high two-dimensional ridges block the flow upstream (Smolarkiewicz and Rotunno 1989; Pierrehumbert and Wyman 1985). Even if the forcing is twodimensional the breaking of gravity waves induces three-dimensional motions (Clark and Farley 1984; Fritts et al. 1996; Afanasyef and Peltier 1998). Considering these processes it seems appropriate to study the propagation of orographic gravity waves into the stratosphere in three spatial dimensions. Technical progress including local grid refinement and increasing computing power made three-dimensional simulations possible with domains extending well into the stratosphere and grids resolving orographic gravity waves (Leutbecher and Volkert 1996).

The demand for mesoscale temperature fields for the interpretation of PSC observations with backscattering lidars motivated several case studies using three-dimensional simulations of orographic flows on domains extending to an altitude of about $30 \mathrm{~km}$ (Dörnbrack et al. 1998; Carslaw et al. 1998b; Wirth et al. 1999; Dörn- brack et al. 1999, all four studies will be referred to as DCWD hereafter). DCWD present three cases of flow over northern Scandinavia, which were simulated at horizontal resolutions ranging from 36 to $4 \mathrm{~km}$. Cold spots of mesoscale extent develop in the stratosphere in these these simulations. The cold spots are collocated with observed regions of PSC formation. The temperature anomalies are caused by adiabatic cooling in mountain waves. In some isolated patches temperatures get low enough for the formation of ice PSCs, which can be identified in lidar data by their large backscattering ratio in the parallel and perpendicular polarization. Based on an estimate for the stratospheric water vapor mixing ratio the temperature at these patches of ice PSCs can be inferred. Together with upstream values of temperature from global analyses the necessary adiabatic cooling can be deduced. This value of cooling is then compared with the numerical simulations. A conclusion from the studies of DCWD is that the simulated cooling due to mountain waves depends on the horizontal resolution. On the finest grid it is largest and attains a large part of the cooling inferred indirectly from the lidar data and global analyses.

To evaluate the three-dimensional simulations of stratospheric mountain waves, DCWD additionally compared the simulated stratospheric temperature field with radiosonde ascents of high vertical resolution. Some of the ascents show oscillations in the profiles of wind and temperature. These oscillations are interpreted as perturbations caused by mountain waves. When the actual slant path of the sondes is accounted for, the simulated profiles reproduce the measured oscillations quite well (e.g., Dörnbrack et al. 1999). However, such an evaluation can only test the consistency of the simulations with the observations along the path of individual sondes. Due to the sparse temporal and spatial distribution of the radiosonde ascents, it appears impossible to disentangle errors in the upstream data used in the simulations from deficiencies in the numerical representation of the wave dynamics.

For the present study the wave event on 6 January 1992 over the southern tip of Greenland has been chosen. The mountain wave was probed during a flight of the ER-2 at an altitude of about $20 \mathrm{~km}$. The measurements are presented by Chan et al. (1993). The in situ measurements and microwave temperature profiler (MTP) data of this case provide a more direct and complete measurement of a stratospheric mountain wave event than the measurements analyzed by DCWD. Furthermore, the distinctly three-dimensional orography at the southern tip distinguishes this case from the other studies. Therefore, this case appears to be well suited for a more rigorous test of the capability to simulate the three-dimensional propagation of orographic gravity waves into the stratosphere in a realistic manner.

The observational data allow the comparison to be focused on vertical displacements of isentropic surfaces and temperature anomalies in the stratosphere. For fu- 

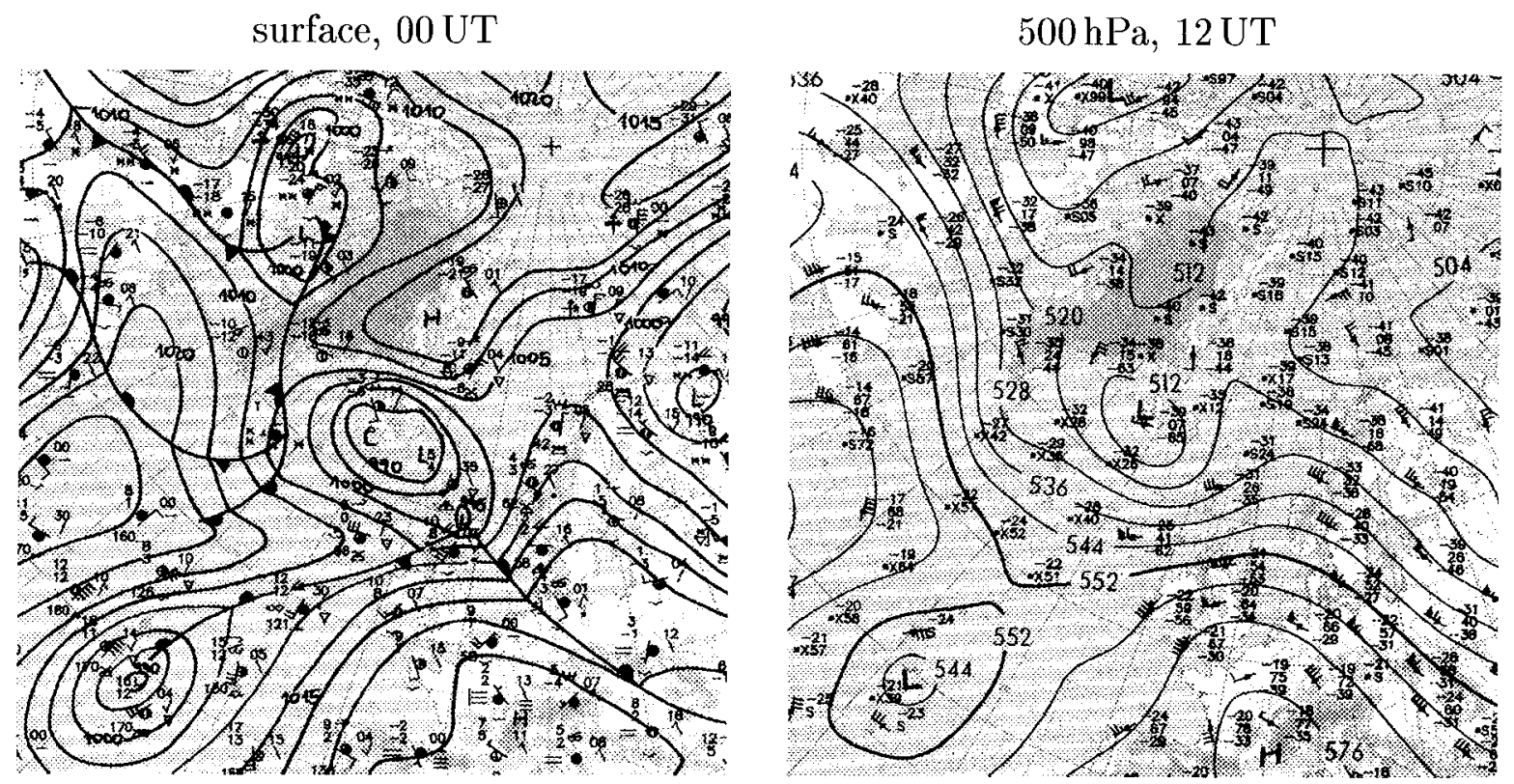

FIG. 1. Observations and manual analysis on 6 Jan 1992 (adapted from Euro. Meteor. Bull., German Weather Service, Offenbach).

ture studies of the effect of mountain waves on microphysical processes in the stratosphere these quantities are of prime importance. The sensitivity of these simulated quantities to parameters of the model setup is examined for parameters that are known to be important. The sensitivity to horizontal resolution noted by DCWD is explored further. Additionally, the effect of surface friction is studied because previous work on flow over mountains in a shallower atmosphere stressed the role of frictional momentum flux at the surface. Georgelin et al. (1994) found that for cases of flow over the Pyrénées an increased surface friction reduces the wave amplitude. This is in accordance with numerical experiments of idealized flow over elliptical ridges by Ólafsson and Bougeault (1997).

The numerical experiments of the present study simulate dry dynamics. Apart from parameterized turbulent friction and surface friction the flow is adiabatic and inviscid. The orography and the upstream conditions are represented in a realistic way as they are seen as the prime factors controlling the generation and propagation of mountain waves. This simulation strategy places the present study between studies of highly idealized flow and case studies with operational numerical weather forecasting models that include diabatic processes due to radiation, moist convection, and surface fluxes of sensible and latent heat.

The synoptic situation and the observational evidence for the mountain wave are summarized in section 2 . The setup of the numerical experiments is described in section 3 . In section 4 the results of the numerical experiments are presented and compared to the observation of the mountain wave in the stratosphere. In section 5 details of the dynamics of the mountain wave event are examined based on the experiment that agrees best with the observations. The results are summarized and discussed in section 6 .

\section{Observations}

Different sources of observational data are available for the case of 6 January 1992: routine soundings, especially the one of Narssarssuaq at the southern tip of Greenland; satellite images; and data taken on a flight of the ER-2 in the stratosphere.

\section{a. Synoptic-scale flow and Narssarssuaq sounding}

The zonal tropospheric flow impinges on the southern tip of Greenland while meandering between $50^{\circ}$ and $65^{\circ} \mathrm{N}$ on 6 January 1992. At higher latitudes, north of $70^{\circ} \mathrm{N}$, there is no significant flow across Greenland's orography in the troposphere (Fig. 1). Upstream of the southern tip, at Hudson Bay and Baffin Island, westerly winds of 40-70 kt prevail at the 500-hPa level, whereas at the southern tip itself a speed of $20 \mathrm{kt}$ has been recorded by the sounding of Narssarssuaq.

In the lowest kilometer the air is almost stagnant at Narssarssuaq according to the 1200 UTC ascent (Fig. 2 ). The speed increases with pronounced shear in the layers of $1-2-$ and $6-8-\mathrm{km}$ altitude. There is little directional wind shear apart from the lowest kilometer. Thus the conditions for the vertical propagation of gravity waves excited by the flow over the 2000-m-high orography downstream of Narssarssuaq are favorable. Vertically propagating gravity waves will be affected by the well-defined thermal tropopause at an altitude of 

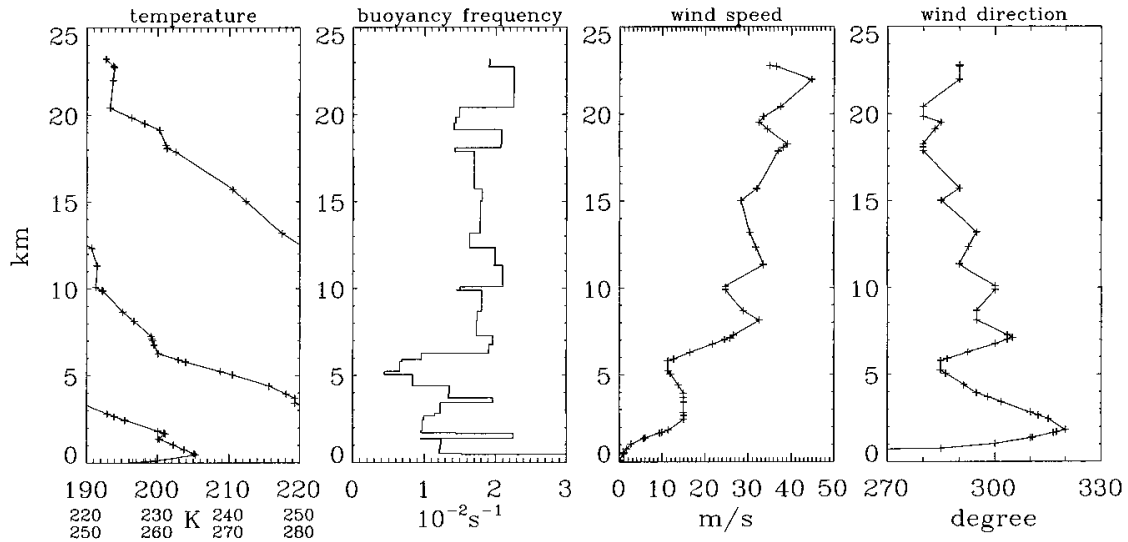

FIG. 2. Sounding from Narssarssuaq $\left(61^{\circ} 11^{\prime} \mathrm{N}, 45^{\circ} 25^{\prime} \mathrm{W}\right)$ at 1200 UTC 6 Jan 1992: Profiles of temperature (scale folded every $30 \mathrm{~K}$ ), buoyancy frequency, wind speed, and direction.

$6.5 \mathrm{~km}$. There the buoyancy frequency increases abruptly from values around 0.01 to $0.02 \mathrm{~s}^{-1}$.

\section{b. Orographic clouds}

Vertical motions in flow past orography often cause the formation of quasi-stationary clouds. These may show up in satellite images, which can be used to infer details of the cloud system such as location, size, and altitude.

The satellite NOAA-11 passed the southern tip of Greenland twice, shortly before and after the mountain wave observation by the ER-2. The images at 1444 and 1626 UTC show a quasi-stationary cloud structure over the eastern slope at about $62.5^{\circ} \mathrm{N}$ (Fig. 3).

Due to the low sun the contrast in the visible channel is sharp. The cloud shadow apparent at its northern edge is used to estimate the cloud altitude. In the 1444 UTC image the shadow is about $30 \mathrm{~km}$ long. As the elevation of the sun is approximately $3.5^{\circ}$ the cloud top is about $2 \mathrm{~km}$ above the surface the shadow is cast on. Assuming that this surface is the ground, which has an elevation of $1.5-2.5 \mathrm{~km}$ at the position of the shadow, the cloud should be located in the lower troposphere at about 600 $\mathrm{hPa}$.

The movement of the cloud pattern is slow. The western edge is about $30 \mathrm{~km}$ farther to the east in the later image. According to the ascent at Narssarssuaq the speed of the westerly flow at $600 \mathrm{hPa}$ is about $15 \mathrm{~m} \mathrm{~s}^{-1}$ (Fig. 2). At this speed an air parcel would be advected $92 \mathrm{~km}$ eastward during the time period separating the images. Therefore, the clouds cannot be advected by the flow. Orographically induced lifting is a plausible explanation for the slow motion of this cloud pattern.

\section{c. Stratospheric mountain wave}

The signatures of a mountain wave were observed on 6 January 1992 between 1600 and 1700 UTC above the southern tip of Greenland during a stratospheric flight of the ER-2. It crossed the region twice at altitudes of about 18 and $20 \mathrm{~km}$. On both crossings the wave was situated at approximately the same location. Here we briefly discuss the observations of the mountain wave, which are presented in more detail by Chan et al. (1993).

The observations comprise in situ measurements of wind velocity $(u, v, w)$ and temperature as well as data from a MTP. Gary (1989) and Denning et al. (1989) describe the MTP system in detail. The instrument is a passive microwave radiometer, which measures at wavelengths of 5.24 and $5.10 \mathrm{~mm}$ at 10 different elevation angles. Temperature profiles are derived by inverting the radiative transfer equation. The profiles are centered around the flight altitude and are $3 \mathrm{~km}$ deep. Every $14 \mathrm{~s}$ a scan is complete yielding a horizontal resolution of 3 $\mathrm{km}$. By assuming hydrostatic balance the height of isentropic surfaces can be calculated from the data.

The ER-2 flew at an angle of about $55^{\circ}$ relative to the mean wind, which came from west-northwest (Figs. 2 and $5 \mathrm{~b}$ ). The dominant part of the orography at the southern tip is a south-north-oriented ridge at $61.0^{\circ} \mathrm{N}$, $44.3^{\circ} \mathrm{W}$. The aircraft crossed the southern tip south of the crest of this ridge (Fig. 5b). Isentropes derived from MTP data and in situ measurements of temperature and vertical wind are shown in Fig. 7a (after Figs. 4a,b in Chan et al. 1993). The apparent horizontal wavelength of the wave is about $60 \mathrm{~km}$. The peak-to-peak vertical displacement of isentropic surfaces attains about $0.8 \mathrm{~km}$

Upstream of the wave from $44.5^{\circ}$ to $43.5^{\circ} \mathrm{W}$ the in situ temperature is around $200 \mathrm{~K}$. At $43.8^{\circ} \mathrm{W}$ it drops by $5 \mathrm{~K}$. To the east of this pronounced minimum the temperature rises by $7 \mathrm{~K}$ over $30 \mathrm{~km}$. Farther to the east, at $42.5^{\circ} \mathrm{W}$, it falls again by $3 \mathrm{~K}$ to a value of 200 $\mathrm{K}$. In regions of falling (rising) temperature updrafts (downdrafts) prevail. In the vicinity of the pronounced temperature minimum at $43.8^{\circ} \mathrm{W}$ significant vertical motion of up to $+2 \mathrm{~m} \mathrm{~s}^{-1}$ and $-5 \mathrm{~m} \mathrm{~s}^{-1}$ occurs.

The vertical displacement of isentropic surfaces derived from MTP data and the in situ temperature are anticorrelated. Assuming a steady adiabatic flow the 
(a)

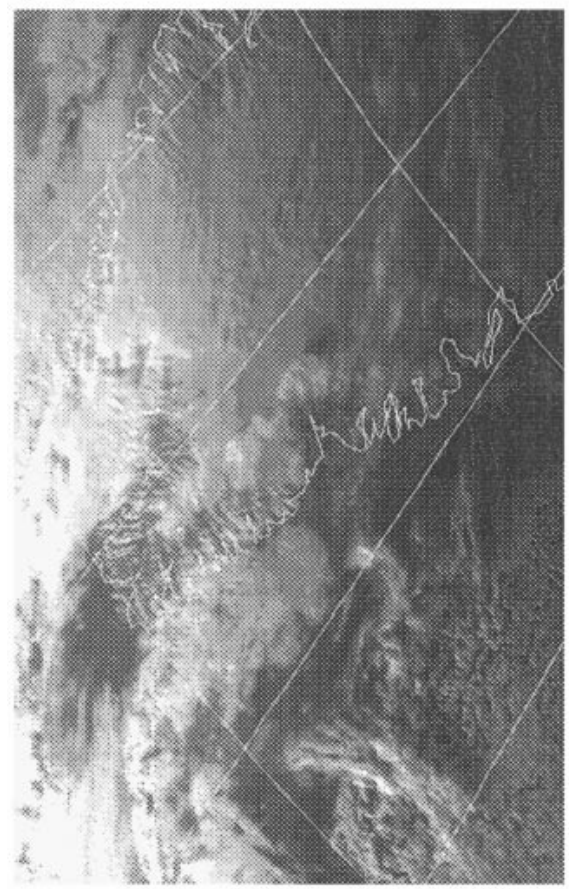

(c)

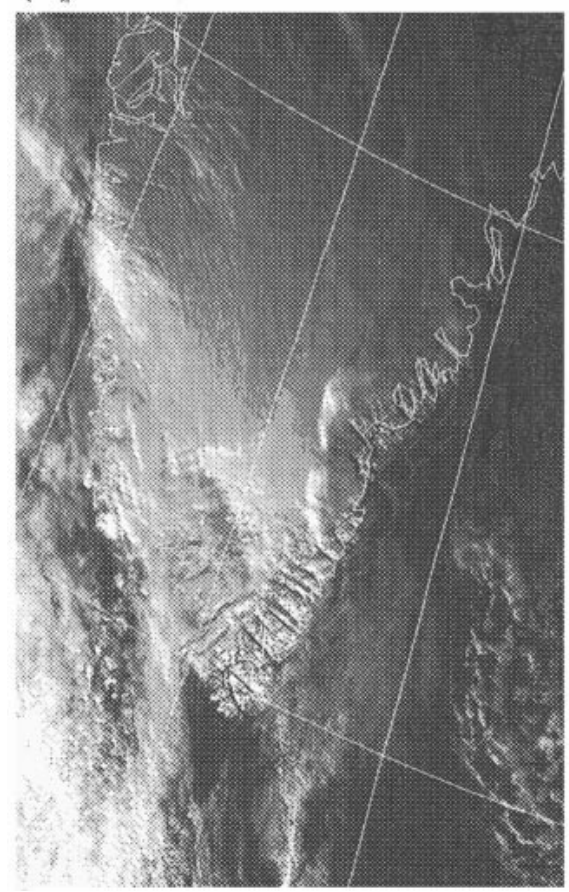

(b)

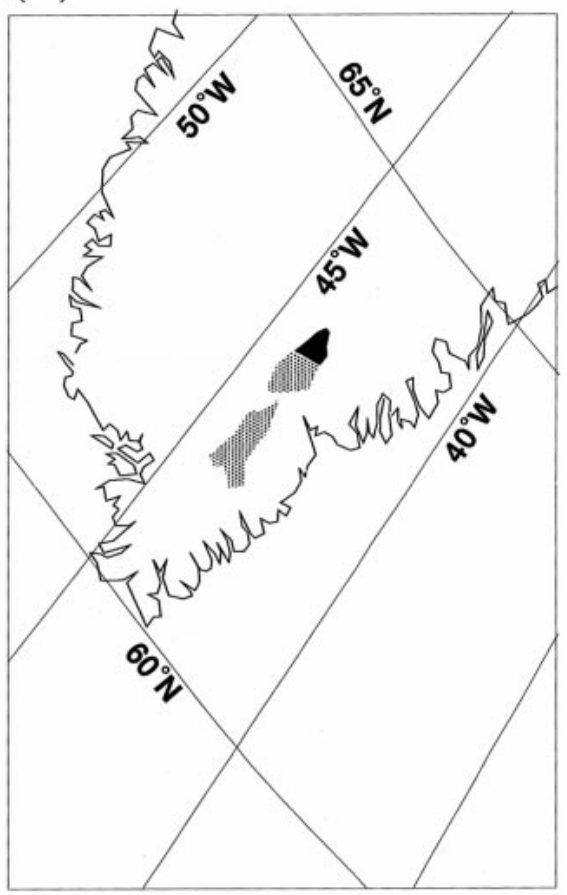

(d)

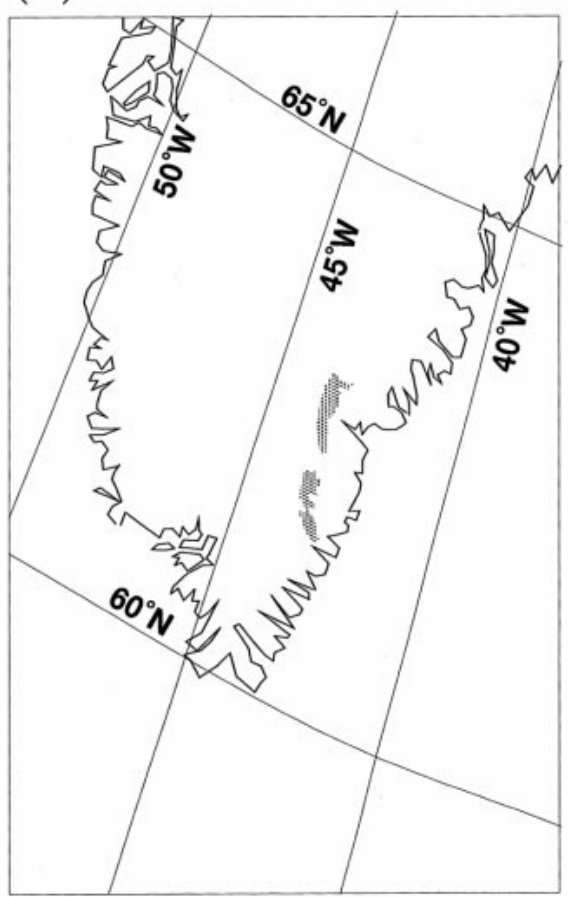

FIG. 3. Visible images from satellite NOAA-11 (channel 2) at (a) 1444 UTC and (c) 1626 UTC 6 Jan 1992. (b) and (d) Subjective analyses of orographic clouds at the corresponding times (stippled) and shadow cast by northern cloud [(b): black]. 

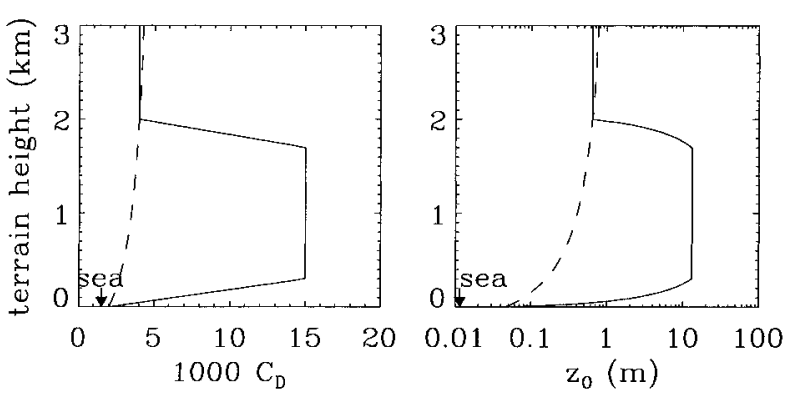

FIG. 4. Variation of drag coefficient $C_{D}$ and roughness length $z_{0}$ with terrain height. Standard scheme (dashed) as used in experiments C, M, and M5, increased friction scheme (solid) as used in experiments $\mathrm{MF}$ and $\mathrm{HF}$.

temperature change $\Delta T$ along an isentropic surface should approximately be given by $-\Gamma \delta$, where $\Gamma=10$ $\mathrm{K} \mathrm{km}^{-1}$ is the dry-adiabatic lapse rate and $\delta$ the vertical displacement of the surface. Overall this relation characterizes the data quite well. For instance, downstream of the pronounced temperature minimum the isentropes drop by 600-900 m, depending on which isentrope is picked. Thus a temperature rise of $6-9 \mathrm{~K}$ would be expected along every isentrope. The observed in situ rise is $7 \mathrm{~K}$. As the ER-2 did not follow an isentropic surface the in situ temperature is additionally affected by the vertical temperature gradient. The isentropic rise is estimated to be $3 \mathrm{~K}$ larger than the in situ rise.

On the return flight, which was on the same track but at a lower altitude, a similar wave signature was observed 44 min later. The earlier and higher observation is $5 \mathrm{~km}$ upstream along the flight track compared to the lower and later one (Fig. 3 in Chan et al. 1993). The relative position of the two encounters is consistent with the presence of a quasi-stationary vertically propagating mountain wave, whose phase lines slope upstream.

The cospectrum of the zonal and the vertical wind component shows a negative correlation at frequencies below $0.07 \mathrm{~s}^{-1}$ corresponding to horizontal wavelengths larger than $3 \mathrm{~km}$. Therefore, there is a downward transport of eastward momentum as it is expected for orographic gravity waves in a westerly flow. The maximum vertical momentum transport takes place at a horizontal wavelength of $60 \mathrm{~km}$ (Fig. 6 in Chan et al. 1993).

In the simulations described next we investigate whether this wave event can be reproduced with a threedimensional numerical model. We will compare the observed and simulated temperature, vertical displacement of isentropic surfaces, and vertical motion quantitatively. This will reveal whether such stratospheric wave events can be simulated in a realistic manner and what sensitivities to horizontal resolution and surface friction have to be expected.

\section{Model configuration}

The flow over Greenland is simulated numerically using a nonhydrostatic compressible model. Five ex-
TABLE 1. Overview of numerical experiments.

\begin{tabular}{lccc}
\hline \hline Exp. & $\Delta x(\mathrm{~km})$ & Surface friction & $\begin{array}{c}\text { Terrain } \\
\text { resolution* }\end{array}$ \\
\hline M5 & 4 & Normal & $5^{\prime}$ \\
C & 12 & Normal & $30^{\prime \prime}$ \\
M & 4 & Normal & $30^{\prime \prime}$ \\
MF & 4 & High & $30^{\prime \prime}$ \\
HF & 1.3 & High & $30^{\prime \prime}$ \\
\hline
\end{tabular}

* Resolution of the terrain elevation data used to derive the model orography in degrees latitude and longitude.

periments are performed to study the sensitivity to surface friction and horizontal resolution (Table 1). We intend to highlight sensitivities that we thought to be major a priori rather than to test many combinations in order to "tune" the model. Therefore we have performed only five experiments. Three of these have a resolution of $4 \mathrm{~km}$ (experiments $\mathrm{M}, \mathrm{M} 5, \mathrm{MF}$ ). Within this group experiment $\mathrm{M}$ can be interpreted as the control run. Experiment M5 tests the impact of using less accurate terrain elevation data for the model orography, whereas experiment MF examines the impact of increasing the surface friction on the slopes. Additionally there are two experiments $(\mathrm{C}, \mathrm{HF})$ with lower and higher horizontal resolution. The pairs of experiments $\mathrm{C}-\mathrm{M}$ and $\mathrm{MF}-\mathrm{HF}$ are used to investigate the sensitivity due to a change of horizontal resolution.

First, we describe the general setup, which all experiments have in common. Then the schemes that parameterize surface friction are explained. Finally, the horizontal meshes and orographies are presented.

\section{a. General setup}

For the numerical experiments the nonhydrostatic version of the National Center for Atmospheric Research-Pennsylvania State University mesoscale model MM5 is used. The model integrates the compressible set of equations in terrain-following coordinates based on a reference state pressure. The prognostic variables are the three velocity components; temperature; and perturbation pressure, which is the deviation of pressure from its reference state value. A general description of the model is given by Grell et al. (1994) and Dudhia (1993). Here we focus on the settings chosen for this study.

As outlined above, radiative heat transfer, surface heat fluxes, and moist thermodynamic processes are not considered to be of prime importance for modeling the generation of mountain waves and their propagation into the stratosphere in this case. Therefore, these processes are not taken into account. This largely simplifies the model physics and eases the interpretation of the results. Such an approach, which relies only on dry dynamics, has already been used for forecasts of stratospheric mountain waves over northern Scandinavia by DCWD.

A fourth-order diffusion is applied in the horizontal 
to ensure numerical stability. The diffusion constant is composed of a background part scaling as $(\Delta x)^{3}$ and a variable part scaling as $(\Delta x)^{4} D$, where $D$ denotes the local rate of deformation of the horizontal velocity field and $\Delta x$ the horizontal mesh size. In the vertical direction subgrid fluxes are represented by a diffusion term $(\partial /$ $\partial z) K_{v}(\partial / \partial z)$. The local bulk Richardson number $\mathcal{R}$ has an influence on the strength of the diffusion through

$$
K_{v}= \begin{cases}K_{0}+l_{K}^{2}\left[\left(\frac{\partial u}{\partial z}\right)^{2}+\left(\frac{\partial v}{\partial z}\right)^{2}\right]^{1 / 2} \frac{\mathcal{R}_{c}-\mathcal{R}}{\mathcal{R}_{c},} & \text { if } \mathcal{R}<\mathcal{R}_{c} \\ K_{0}, & \text { if } \mathcal{R} \geq \mathcal{R}_{c},\end{cases}
$$

where the value of the critical Richardson number is $\mathcal{R}_{c}$ $=0.8$, the length scale is $l_{K}=40 \mathrm{~m}$, and the constant part of the diffusion coefficient is $K_{0}=0.6 \mathrm{~m}^{2} \mathrm{~s}^{-1}$. The dry-adiabatic adjustment scheme in the model has been switched off, to avoid an artificial damping of breaking mountain waves.

In the stratosphere a relatively high vertical resolution is necessary in order to resolve gravity waves, as their vertical wavelength is small due to the high static stability. Therefore, an approximately equidistant spacing of $\Delta z=0.6 \mathrm{~km}$ has been chosen for the coordinate surfaces throughout the model atmosphere. There are 53 levels in total (except for one sensitivity experiment with 100 levels). The model top is at $10 \mathrm{hPa}$, which is at approximately $30 \mathrm{~km}$.

A radiation condition is used at the model top to avoid the reflection of vertically propagating gravity waves. The upper boundary condition is derived from linear theory of hydrostatic gravity waves in a nonrotating atmosphere. Klemp and Durran (1983) show that the condition provides reasonable results, even if nonhydrostatic, Coriolis, or nonlinear effects are affecting the gravity waves.

Initial conditions and lateral boundary data are derived from 12-hourly analyses of the European Centre for Medium-Range Weather Forecasts (ECMWF). They have a resolution of $2.5^{\circ}$ lat $\times 2.5^{\circ}$ long and are available at 14 standard pressure levels from 1000 to $10 \mathrm{hPa}$. In order to allow sufficient time for the spinup, that is, the propagation of orographic gravity waves into the stratosphere, the model is initialized at 0000 UTC 6 January 1992. The simulations end at 1800 UTC that day.

\section{b. Surface friction schemes}

Momentum transfer into the lowest model layer by surface friction is represented by a bulk formula of the form

$$
\left(\tau_{x}, \tau_{y}\right)=-\rho C_{D}\left(u^{2}+v^{2}\right)^{1 / 2}(u, v),
$$

where $\left(\tau_{x}, \tau_{y}\right)$ denote the surface flux of momentum due to friction, $\rho$ density, and $(u, v)$ the horizontal component of velocity in the lowest model layer. The drag coefficient $C_{D}$ varies with terrain height. Two different schemes are employed (Fig. 4). The standard surface friction scheme has a drag coefficient increasing monotonically with terrain height, whereas the increased surface friction scheme is characterized by a considerably larger drag coefficient at elevations from 300 to 1700 $\mathrm{m}$. The latter scheme results in enhanced friction on the rugged slopes of Greenland. This variation with terrain elevation is probably more realistic than the friction prescribed by the former scheme, which has a rather low drag coefficient on the slopes and a maximum of the drag coefficient on the ice cap. In the increased surface friction scheme the drag coefficient is set to a large value on the slopes in order to accentuate the impact that a change of surface friction within physically reasonable bounds has on the simulated mountain wave.

The drag coefficient $C_{D}$ can be converted into a roughness length $z_{0}$. For this conversion we assume a neutral boundary layer with a logarithmic wind profile $u(z)=$ $(\tau / \rho)^{1 / 2} k^{-1} \ln \left(z / z_{0}\right)$, where $k=0.4$ is the von Kármán constant (Stull 1988). The roughness length is obtained as $z_{0}=z_{1} \exp \left(-k C_{D}^{-1 / 2}\right)$ by inserting the wind $u\left(z_{1}\right)$ into (2), where $z_{1}=350 \mathrm{~m}$ is the height of the lowest model layer above ground. Maximum values of the roughness length are 0.8 and $13 \mathrm{~m}$ for the normal and increased surface friction schemes, respectively (Fig. 4). As the parameterization of surface friction ignores the influence of static stability and the lower troposphere over Greenland is quite stable during the considered case, the increased surface friction scheme ensures a large frictional momentum transfer.

\section{c. Horizontal meshes and orographies}

The model domain is centered at the southern tip of Greenland, where the mountain wave was observed. Baffin Island and Iceland are on the western and eastern boundary of the domain, respectively (D1 in Fig. 5a). It has a horizontal resolution of $\Delta x=36 \mathrm{~km}$ and a size of $2200 \mathrm{~km} \times 2200 \mathrm{~km}$.

In the vicinity of the southern tip the horizontal mesh is locally refined [Grell et al. (1994), two-way nesting]. Numerical experiments with one, two, and three levels of refinement are presented (domains D2, D3, D4 in Fig. 5a). Each level of mesh refinement increases the horizontal resolution by a factor of 3 . The set of experiments is listed in Table 1. The first letter of the experiment labels- $\mathrm{C}, \mathrm{M}$, or $\mathrm{H}-$ indicates coarse, medium, or high resolution, respectively. The region covered by the innermost domain D4 $(\Delta x=1.3 \mathrm{~km})$ is shown in Fig. 5 b.

The model orography has been derived from terrain elevation datasets with $30^{\prime \prime}$ and $5^{\prime}$ resolution in latitude and longitude. The $5^{\prime}$ data stem from a global dataset provided by the Geophysical Data Center, Boulder, Colorado. The model orography at $4-\mathrm{km}$ resolution derived from the $5^{\prime}$ data (Fig. 5c) was compared with topographic 
(a)

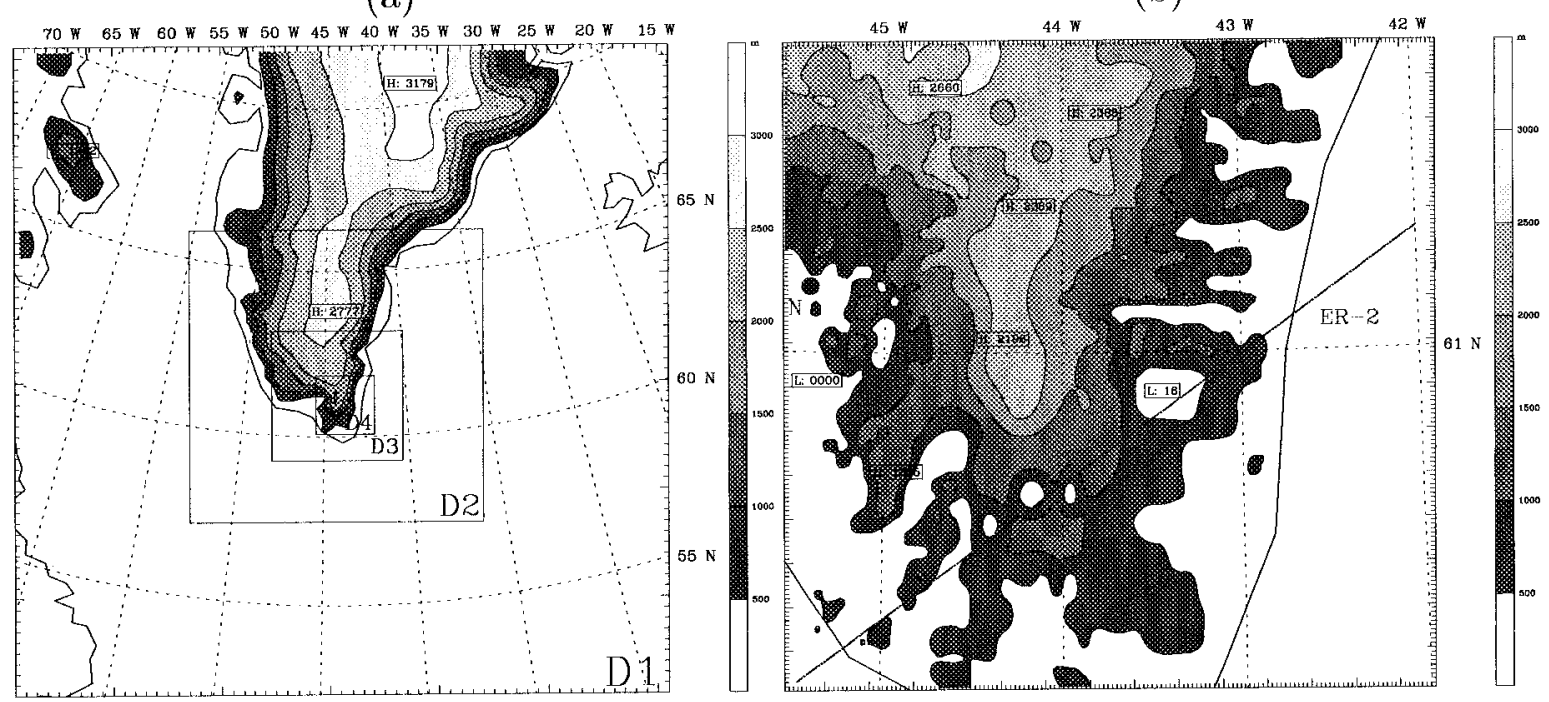

(c)

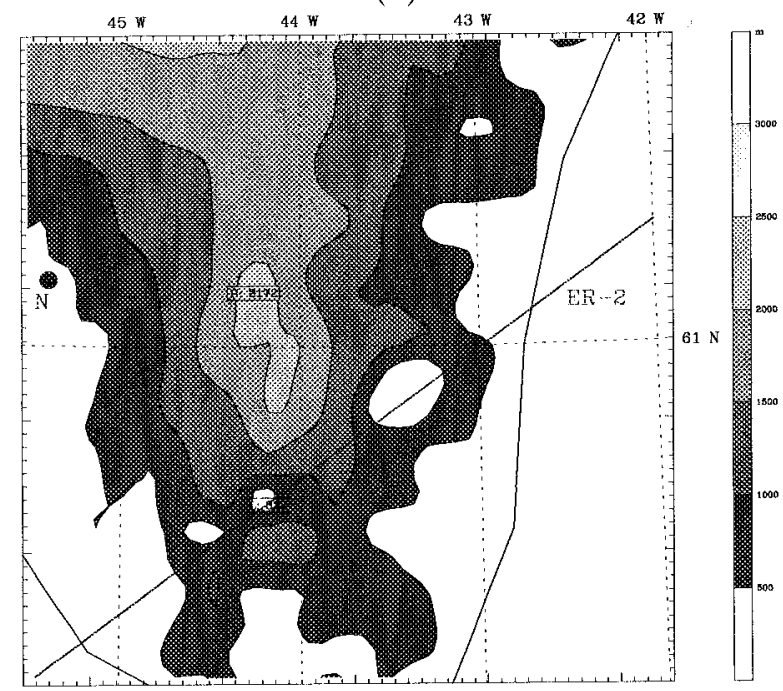

FIG. 5. Model domain, regions of grid refinement, and orography. (a) The entire domain D1 with mesh size $\Delta x=36 \mathrm{~km}$ and regions D2, D3, and D4 of grid refinement to mesh sizes of 12, 4, and 1.3 km, respectively; size of D1: $2160 \mathrm{~km} \times 2160 \mathrm{~km}$; size of D4: $200 \mathrm{~km} \times$ $200 \mathrm{~km}$. (b) The model orography in region D4 for experiment HF with radiosonde station Narssarsuaq (N) and flight track of the ER-2 (solid line); (c) as in (b) but for experiment M5.

maps of the southern tip of Greenland at a scale of 1: 250000 available from the Danish Geodetic Institute. The comparison suggested that a higher-resolution dataset is required for mesh sizes of less than about $4 \mathrm{~km}$.

Therefore, 30" data were obtained from the Earth Resources Observation System of the U.S. Geological Survey, Sioux Falls, South Dakota. Apart from a data-void region south of $61^{\circ} \mathrm{N}$ and east of $44^{\circ} \mathrm{W}$ these data agree better with the topographic maps than the $5^{\prime}$ data. The data void was removed by inserting the coarser $5^{\prime}$ data. These fudged $30^{\prime \prime}$ data were then used in all experiments except experiment M5. The model orography of the finest mesh, domain D4 $(\Delta x=1.3 \mathrm{~km})$, is shown in Fig. $5 \mathrm{~b}$.
In all experiments domains D1-3 $(\Delta x \geq 4 \mathrm{~km})$ are initialized at 0000 UTC 6 January 1992. In experiment $\mathrm{HF}$ the innermost grid D4 $(\Delta x=1.3 \mathrm{~km})$ is initialized at 1200 UTC by interpolating the fields from the coarser mesh D3.

\section{Sensitivity experiments}

Now, we present the results of the five numerical experiments. First, we examine the effect of surface friction and horizontal resolution on the simulated mountain wave in the stratosphere. Furthermore, we inspect the level of agreement with the measurements 
TABLE 2. Timescales of diffusion $\tau_{d}$, advection $\tau_{a}$, and wave propagation $\tau_{p}$ in $10^{3} \mathrm{~s}$. Horizontal wavelength $\lambda$ (in $\mathrm{km}$ ) used for the estimates.

\begin{tabular}{lccccc}
\hline \hline Exp. & $\lambda$ & $\lambda / \Delta x$ & $\tau_{d}$ & $\tau_{a}$ & $\tau_{p}$ \\
\hline HF & 27 & 20 & 33 & 1.4 & 3.2 \\
MF & 27 & 6.7 & 1.3 & 1.4 & 3.2 \\
M & 42 & 10.5 & 7.8 & 2.1 & 5.0 \\
C & 42 & 3.5 & 0.3 & 2.1 & 5.0 \\
\hline
\end{tabular}

from the ER-2. Next, the causes for the sensitivity to horizontal resolution and surface friction are analyzed. Finally, the mean static stability in the vicinity of the observed wave is discussed.

\section{a. Comparison with observed mountain wave}

In all experiments orographic gravity waves are generated at the southern tip and propagate into the stratosphere reaching the ER-2 flight level. Changes of horizontal resolution and surface friction change the location of the dominant simulated wave in the stratosphere only insignificantly. The locations of the simulated waves differ less than about $20 \mathrm{~km}$ from the location of the observed wave.

However, the wave amplitude is strongly affected by changes of horizontal resolution or surface friction. The maximum upward and downward displacements of an isentropic surface along the flight path are used as measure of the simulated stratospheric wave amplitude (Fig. 6). For this comparison the $460-\mathrm{K}$ isentrope is selected. It is close to the ER-2 flight level (Fig. 7). Displacements are calculated as height deviation from an inclined plane, which is closest to the $460-\mathrm{K}$ isentropic surface over the region of domain D4. Maxima slightly off the flight track are included by evaluating maximum displacements within a $20-\mathrm{km}$-wide corridor around the flight path. No experiment overestimates the wave amplitude and only the coarse resolution experiment $\mathrm{C}$ underestimates the amplitude considerably. The peak-topeak amplitude of vertical displacement in experiment $\mathrm{C}$ reaches only $27 \%$ of the observed $0.8 \mathrm{~km}$. In the other experiments the peak-to-peak amplitude attains a larger fraction of the observed value (experiments HF: 92\%, MF: $62 \%$, M: $98 \%$, and M5: 108\%).

The detailed structure of the stratospheric mountain wave in these four experiments is presented next and compared to the observations. Over a period of $30 \mathrm{~min}$ the model fields hardly change. This justifies a comparison of simulation results valid at 1600 UTC with observations in the period of 1558-1615 UTC. As proxy to the in situ observations of vertical wind and temperature, model data interpolated to an altitude of 19.8 $\mathrm{km}$ are used. Thereby, the variation of flight altitude of about $\pm 0.3 \mathrm{~km}$ is neglected.

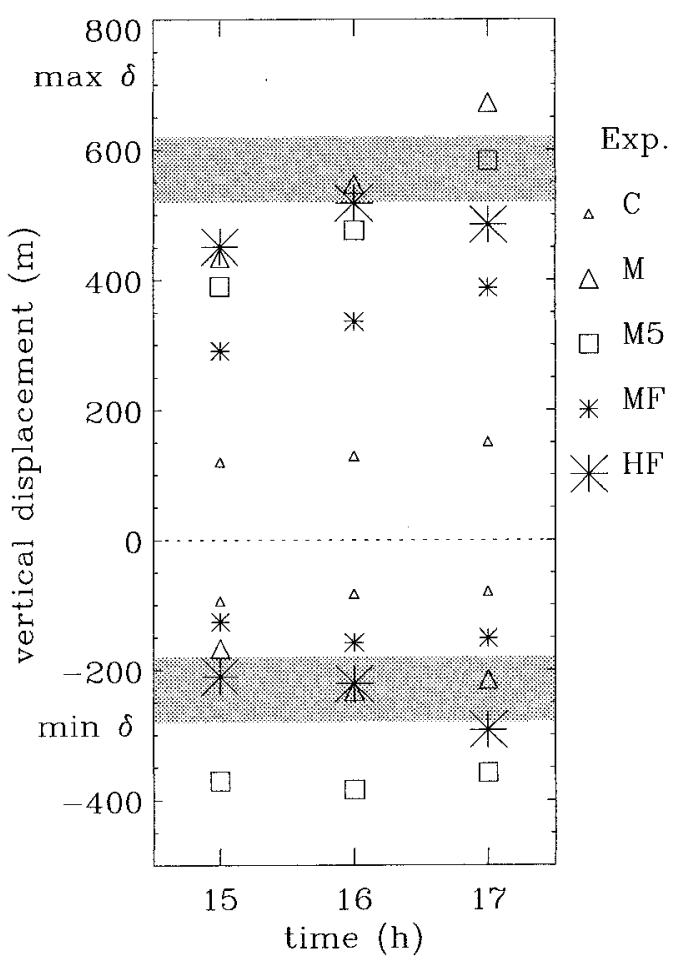

FIG. 6. Maximum upward $(\max \delta)$ and downward $(\min \delta)$ displacements of the $460-\mathrm{K}$ isentropic surface in the vicinity of the ER2 flight track for the five simulations at 1500, 1600, and 1700 UTC. See text for details about the calculation of vertical displacements. Shaded bars indicate approximate maximum displacements determined from the MTP data in Fig. 7a.

\section{1) EXPERIMENT HF}

The signatures of the mountain wave in simulation HF are very similar to the observed signatures (Figs. $7 \mathrm{a}, \mathrm{b})$. The salient feature is the upward displacement of isentropic surfaces at $43.8^{\circ} \mathrm{W}$, which is correlated with a temperature minimum and an updraft and a downdraft on the upstream and downstream side, respectively. The temperature drop relative to upstream values amounts to about $5 \mathrm{~K}$ in both simulation and observation. The simulated temperature minimum lies $11 \mathrm{~km}$ farther upstream than the observed one. Downstream of the minimum a warming of $5 \mathrm{~K}$ is simulated, whereas a temperature rise of $7 \mathrm{~K}$ was observed.

Farther downstream at about $42.4^{\circ} \mathrm{W}$ there is another distinct feature present in simulation and observation. The simulated (observed) temperature falls by 2.5 (3.5) $\mathrm{K}$. The simulated drop is $7 \mathrm{~km}$ too far downstream compared to the observation.

The simulation does not reproduce the observed variations of vertical velocity and potential temperature at horizontal scales smaller than about $10 \mathrm{~km}$. The simulated fields are smoother. As a consequence, the horizontal gradients of the simulated fields are smaller. Furthermore, the strong and narrow downdraft with an observed maximum of $-4.8 \mathrm{~m} \mathrm{~s}^{-1}$ attains only $-2.7 \mathrm{~m}$ $\mathrm{s}^{-1}$ in the simulation. 
(a) Obs.

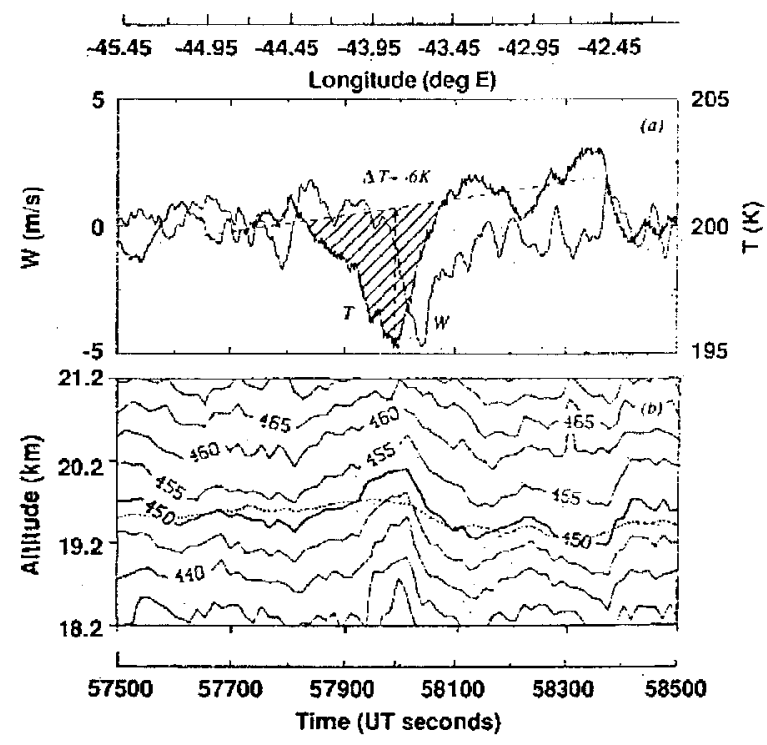

(c) Exp. M

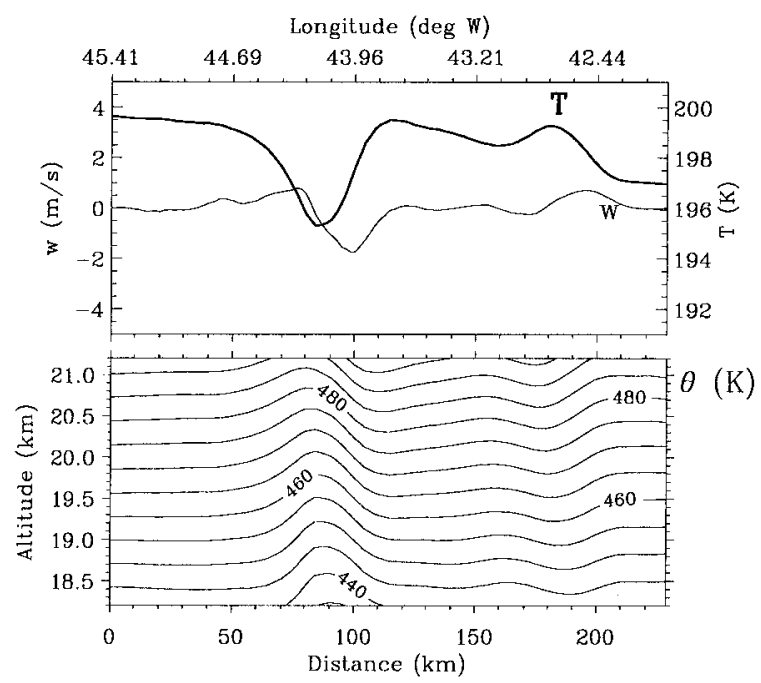

(b) Exp. HF

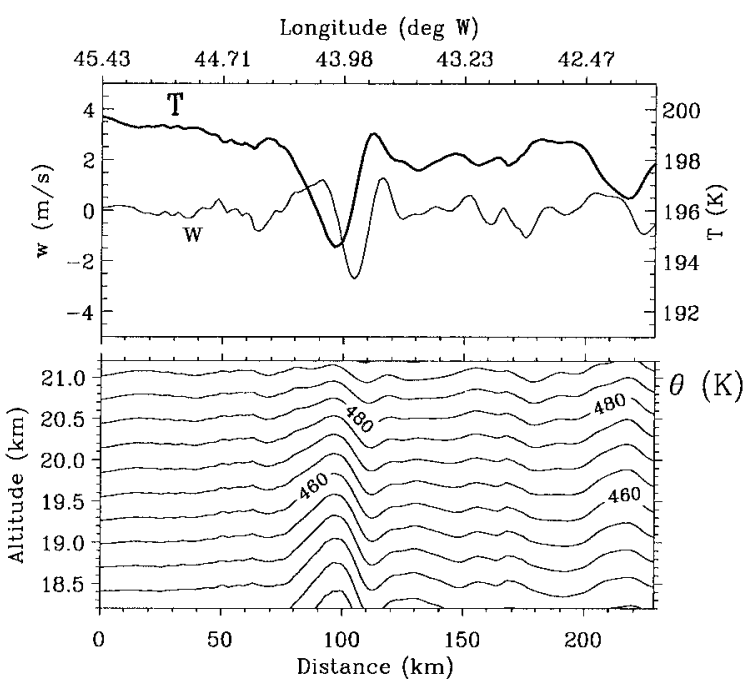

(d) Exp. MF

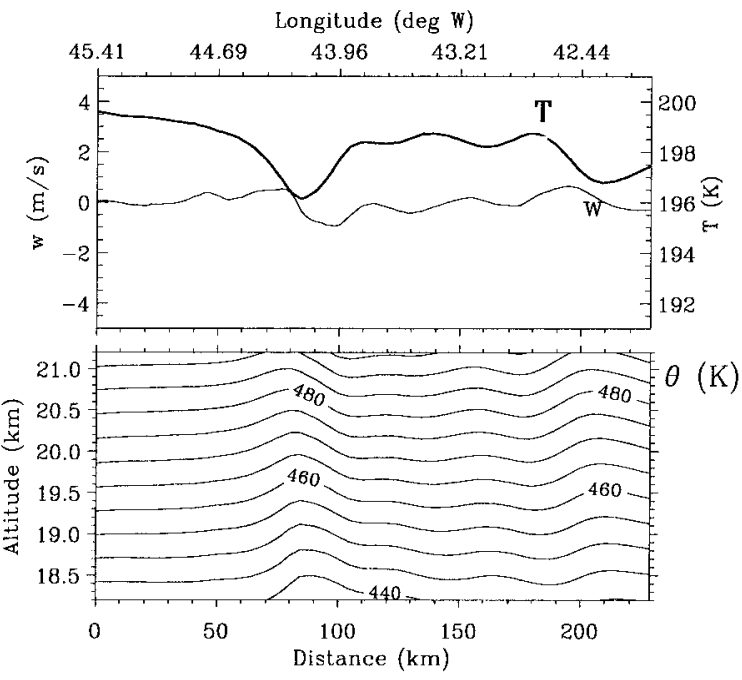

FIG. 7. (a) Observations vs (b)-(d) simulations of the stratospheric mountain wave. (top subpanels) Temperature $T$ and vertical velocity $w$ along the ER-2 flight track and (bottom subpanels, every $5 \mathrm{~K}$ ) isentropes in a vertical section. The flow is from left to right; see Fig. 5 for the baseline of the section. (a) The (top) in situ and (bottom) MTP measurements from the ER-2 flight between 1558 and 1615 UTC; (dotted, bottom) flight altitude [adapted from Chan et al. (1993)]. (b)-(d) The simulated wave at 1600 UTC in simulations HF, M, and MF, respectively.

Noise in the temperature field retrieved from the MTP data may account for some of the small-scale variance in the potential temperature. However, at some places small horizontal scales appear to represent real structures of the flow. The sudden upward displacements of isentropic surfaces at $44.0^{\circ}$ and $42.4^{\circ} \mathrm{W}$ occur over some depth and look like small hydraulic jumps. The jump at $42.4^{\circ} \mathrm{W}$ was passed by the flight track and the MTP data are corroborated by the in situ observations, as there is a large negative gradient of temperature and an updraft of $1.5 \mathrm{~m} \mathrm{~s}^{-1}$.
The mean static stability in all simulations is considerably lower in the altitude range from 18.2 to $21.2 \mathrm{~km}$ than the mean static stability derived from the MTP data displayed in Fig. 7a $\left[\Delta \theta / \Delta z=50 \mathrm{~K}(3 \mathrm{~km})^{-1}\right.$ vs $35 \mathrm{~K}$ $(3 \mathrm{~km})^{-1}$ ]. This difference will be further dealt with at the end of this section.

\section{2) EXPERIMENT MF}

In experiment MF the same surface friction scheme as in HF has been employed yet the resolution is coarser. 
TABLE 3. Buoyancy frequency $N\left(10^{-2} \mathrm{~s}^{-1}\right)$ in the layer between altitude $z_{1}$ and $z_{2}(\mathrm{~km})$.

\begin{tabular}{lccc}
\hline \hline & $z_{1}$ & $z_{2}$ & $N$ \\
\hline Simulation $^{a}$ & 18.2 & 21.2 & 1.94 \\
ER-2 data & & & \\
$\quad$ MTP $^{b}$ & 18.2 & 21.2 & 1.59 \\
MTP $^{c}$ & 19.4 & 20.1 & $1.86 \pm 0.14$ \\
In situ T $^{d}$ & 17.5 & 19.7 & 1.92 \\
Sonde $^{e}$ & 18.1 & 19.1 & 2.07 \\
& 19.1 & 20.4 & 1.45 \\
& 20.4 & 22.7 & 2.25 \\
\hline
\end{tabular}

${ }^{a}$ From Fig. 7b.

${ }^{b}$ From Fig. 7a.

${ }^{c}$ From range of vertical temperature gradients given in Fig. $7 d$ in Chan et al. (1993). The temperature gradient appears to be determined from the channels of the MTP adjacent to the flight level as in the example given by Gary (1989).

${ }^{d}$ From temperature difference at $43.7^{\circ} \mathrm{W}$ taken from Fig. $3 \mathrm{~b}$ in Chan et al. (1993).

${ }^{e}$ From 1200 UTC radiosonde launched at Narssarssuaq.

This affects the amplitude of the wave but not the horizontal phase structure of the wave. Only the smaller horizontal scales are absent, which results in even smoother fields (Figs. 7a,b,d). An upstream tilt of the wave is apparent in contrast to simulation HF and the MTP data. In the temperature trace a minimum lies at $44^{\circ} \mathrm{W}$ and a distinct drop at $42.5^{\circ} \mathrm{W}$, farther upstream than in experiment HF. The minimum and the drop are located farther upstream than the corresponding features in the observation by 23 and $5 \mathrm{~km}$, respectively. The amplitude of the wave at $44^{\circ} \mathrm{W}$ attains only $62 \%$ of the observed value, whereas the amplitude of the upward displacement at $42.5^{\circ} \mathrm{W}$ is quite unaffected by the coarser resolution.

\section{3) EXPERIMENT M}

This experiment is identical to MF apart from the lower surface friction on the slopes. Regarding the wave phase, the horizontal scales, and the locations of the temperature minimum and drop, the results are very similar to experiment MF (Figs. 7c,d). The obvious difference is the amplitude of the wave at $44^{\circ} \mathrm{W}$. The amplitude is similar to that of experiment HF; the peakto-peak amplitude attains $98 \%$ of the observed value. The temperature drop at $42.5^{\circ} \mathrm{W}$ is changed only little by reducing the surface friction.

\section{4) EXPERIMENT M5}

For this simulation the lower-resolution $5^{\prime}$ terrain elevation data have been used to derive the model orography (Figs. 5b,c). All other settings are equal to those of experiment M. The peak-to-peak amplitude reaches $108 \%$ of the observed value. The different orography mainly results in a change of wave phase. As a result the maximum downward displacement of the $460-\mathrm{K}$ is- entrope is larger than that of the other experiments (Fig. 6). The wave at $44^{\circ} \mathrm{W}$ appears in the observation as well as in the other simulations as isolated upward displacement of the isentropic surfaces. In experiment M5 (vertical section not shown) an upward displacement of 0.4 $\mathrm{km}$ is simulated at $44^{\circ} \mathrm{W}$. This is followed immediately by a downward displacement of $0.7 \mathrm{~km}$ and another upward displacement of $0.4 \mathrm{~km}$. Thus the misspecification of details of the orographic shape results in an erroneous wave phase in the stratosphere.

\section{b. Horizontal resolution and diffusion}

The pairs of experiments MF-HF and $\mathrm{C}-\mathrm{M}$ reveal that an increased horizontal resolution results in larger mountain wave amplitudes in the stratosphere. Already at a resolution of $\Delta x=12 \mathrm{~km}$ (experiment $\mathrm{C}$ ) the main ridge at the southern tip is reasonably resolved. Increasing the resolution to $4 \mathrm{~km}$ and further to $1.3 \mathrm{~km}$ adds some orographic details. Parts of the slopes get steeper (Fig. 8). As the main ridge is broad enough it is only marginally lowered by the smoothing required at the coarsest horizontal resolution. The change of orography itself seems to be insufficient to explain the strong dependence of stratospheric wave amplitude on horizontal resolution. Here we examine whether this sensitivity can be caused by diffusion in the numerical model.

The spatial scales of motions resolved in the numerical model have a lower limit due to the grid spacing. A wavelength less than $2 \Delta x$ cannot be resolved on a grid of mesh size $\Delta x$. In addition, finite differencing errors are very large for waves with wavelength close to $2 \Delta x$. Therefore, the smallest scales are removed by applying a hyperdiffusion in the horizontal. The diffusion constant is set according to the mesh size. Furthermore, a direct orographic forcing of wavelengths close to $2 \Delta x$ is reduced by smoothing the model terrain.

Short waves with horizontal wavelength $\lambda$ greater than approximately $4 \Delta x$ are forced directly by the orography and indirectly by the nonlinear dynamics. These short waves are affected by the diffusion in the model. Here the effect of the explicit horizontal diffusion is analyzed. It is implemented as fourth-order diffusion term $K \Delta^{2} \phi$ for every prognostic variable $\phi$ of the model, where $\Delta=\partial^{2} / \partial x^{2}+\partial^{2} / \partial y^{2}$ denotes the horizontal Laplacian. This diffusion strongly depends on the horizontal resolution. For a wave of small to moderate amplitude in an ambient flow with a low rate of deformation the background term of the hyperdiffusion will dominate. Its diffusion constant $K_{b}$ is set to

$$
K_{b}=3 \times 10^{-3}(\Delta x)^{4} / \Delta t .
$$

The time step $\Delta t$ is chosen proportional to the mesh size to guarantee numerical stability. We use $\Delta t=0.25 \Delta x /$ $c_{s}$, where $c_{s} \approx 300 \mathrm{~m} \mathrm{~s}^{-1}$ denotes the speed of sound. Thus the diffusion constant turns out to be proportional to the mesh size cubed $K_{b}=4 \mathrm{~m} \mathrm{~s}^{-1}(\Delta x)^{3}$. In consequence a wave of fixed horizontal wavelength $\lambda$ ex- 
(a) Exp. HF

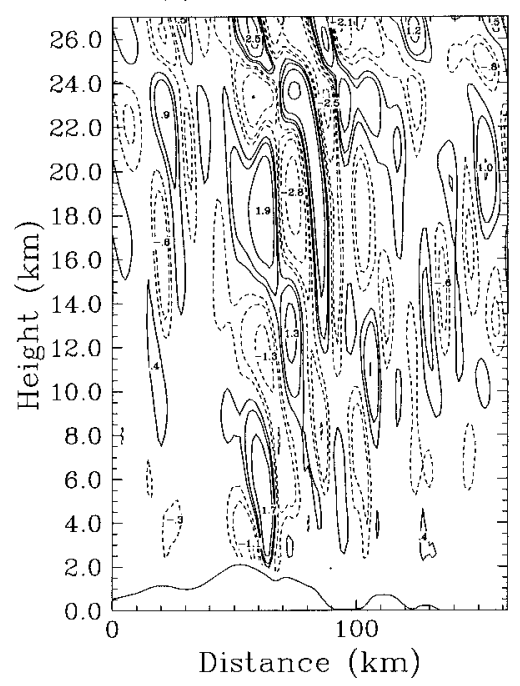

(c) $\quad$ Exp. M

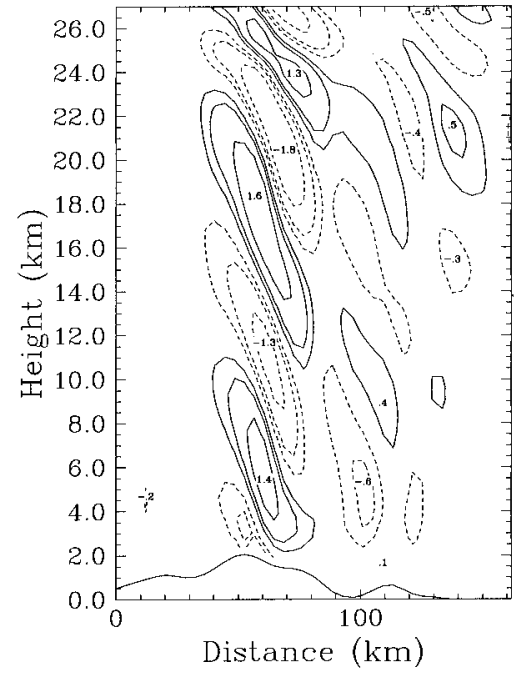

(b) Exp. MF

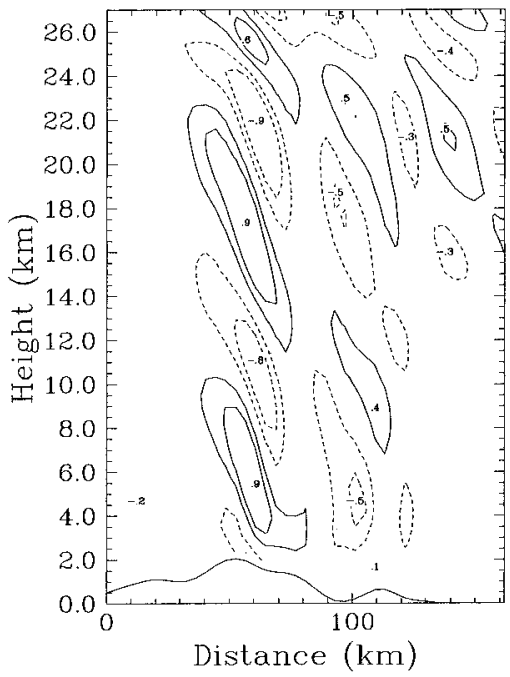

(d) Exp. C

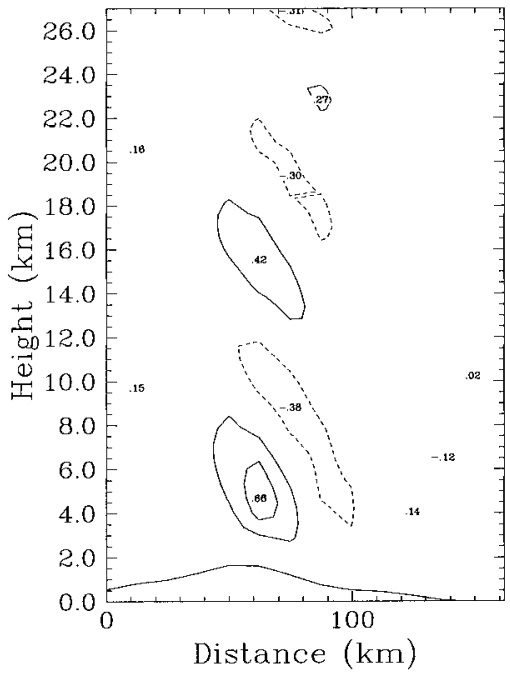

FIG. 8. Sensitivity of mountain wave updrafts (solid) and downdrafts (dashed) to horizontal resolution. Vertical velocity in west-east section along $60.85^{\circ} \mathrm{N}$ at 1600 UTC with logarithmic contour value spacing: $\pm 0.25,0.5,1.0,2.0 \mathrm{~m} \mathrm{~s}^{-1}$. (a) and (b) Experiments $\mathrm{HF}$ and MF with mesh size $\Delta x=1.3$ and $4 \mathrm{~km}$, respectively. (c) and (d) Experiments $\mathrm{M}$ and $\mathrm{C}$ with mesh size $\Delta x=4$ and $12 \mathrm{~km}$, respectively.

periences stronger damping when simulated on a coarser grid. In order to quantify the importance of the diffusion the $e$-folding timescale of the horizontal hyperdiffusion $\tau_{d}$ is calculated and compared to the timescale of advection $\tau_{a}$ and the timescale of energy propagation $\tau_{p}$ of an orographic gravity wave to an altitude of $20 \mathrm{~km}$.

The $e$-folding timescale for damping a wave of horizontal wavelength $\lambda$ by the horizontal diffusion is given by

$$
\tau_{d}^{-1}=K_{b}(2 \pi / \lambda)^{4} .
$$

The horizontal wavelength of the dominant wave directly over the crest at $44^{\circ} \mathrm{W}$ is estimated to $27 \mathrm{~km}$ for experiment $\mathrm{HF}$ and $42 \mathrm{~km}$ for experiment $\mathrm{M}$ to calculate the diffusion timescale (Fig. 8). These wavelengths are used as well for the corresponding coarser resolution experiments $\mathrm{MF}$ and $\mathrm{C}$. The timescale of advection is calculated as $\tau_{a}=\lambda / u$, where a mean wind speed $u=$ $20 \mathrm{~m} \mathrm{~s}^{-1}$ is used. The timescale of gravity wave propagation to an altitude $z$ is $\tau_{p}=z / c_{g z}$, where $c_{g z}=$ $2 \pi u^{2}(N \lambda)^{-1}$ denotes the vertical component of group velocity. Here the propagation timescale is calculated for an altitude of $z=20 \mathrm{~km}$. This altitude corresponds to the flight altitude of the ER-2. The modification of the group velocity by nonhydrostatic and Coriolis effects is neglected as they are small at the wavelengths 
considered. The same wind speed as for the advection timescale and a mean buoyancy frequency $N=0.015$ $\mathrm{s}^{-1}$ are used for the group velocity. In Table 2 the estimates for the three timescales are given for the experiments $\mathrm{HF}, \mathrm{MF}, \mathrm{M}$, and $\mathrm{C}$.

The high-resolution experiment HF is the only experiment in which the hyperdiffusion does not attenuate the main wave. The timescale of diffusion exceeds the timescales of advection and propagation by an order of magnitude (Table 2). In experiment MF the diffusion and advection timescales are about equal. The propagation timescale is larger than twice the diffusion timescale. Therefore, the shorter waves in simulation MF are strongly damped by the horizontal hyperdiffusion. In experiment $\mathrm{M}$ the timescales of hyperdiffusion and propagation are similar, whereas in experiment $\mathrm{C}$ the timescale of propagation is an order of magnitude larger than the scale of hyperdiffusion. From the comparison of the timescales it is evident that the horizontal hyperdiffusion is a major cause of the different stratospheric wave amplitude in the pairs of experiments MF$\mathrm{HF}$ and $\mathrm{C}-\mathrm{M}$.

\section{c. Surface friction and wave generation}

Apart from the difference in the drag coefficient the setup of experiments $M$ and MF is identical. Here we provide a qualitative explanation for the larger amplitude and larger horizontal wavelength of the dominant mountain wave in experiment M (cf. Fig. 8).

Due to the reduced momentum extraction from the surface layer in experiment $\mathrm{M}$, the surface wind on the downslope is stronger and extends farther downstream. Specifically, in experiment $M$ the flow separates from the lee slope at kilometer 68 (Fig. 9a) in contrast to kilometer 60 in MF (Fig. 9b). This difference in flow separation and the difference in the zonal velocity component near the ground (Fig. 9c) are associated with a stronger and broader downward motion over the lee slope in experiment M compared to MF (Fig. 9d). This more pronounced vertical motion explains the larger amplitude of the excited mountain wave. The difference in wave amplitude is maintained during the vertical propagation of the wave (Fig. 9e). Thus the smaller wave amplitude in experiment MF at an altitude of 20 $\mathrm{km}$ results from the weaker orographic wave generation, which is caused by the increased surface friction. In addition to the weaker wave generation in experiment MF the wave in that experiment is somewhat more attenuated by the horizontal hyperdiffusion as its horizontal wavelength is slightly smaller.

\section{d. Mean static stability and wave amplitude}

The simulations exhibit a considerably higher mean static stability in the layer from 18.2 - to $21.2-\mathrm{km}$ altitude than the MTP data displayed in Fig. 7a. Table 3 gives the corresponding values of the buoyancy frequency.

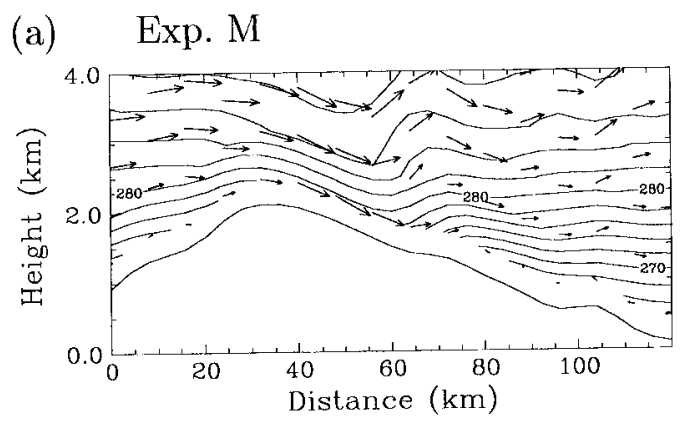

(b) Exp. MF

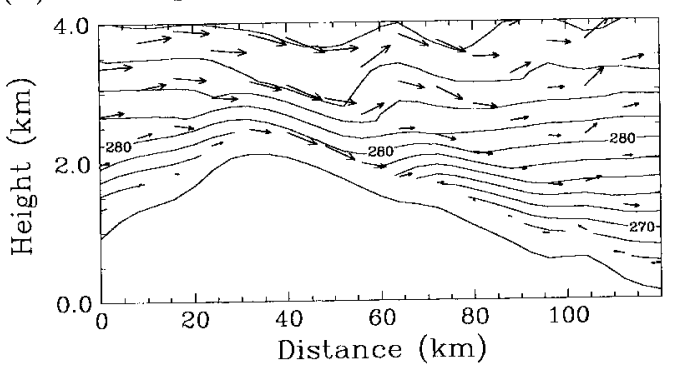

(c)

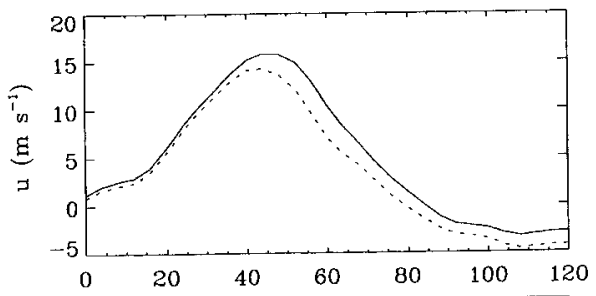

(d)

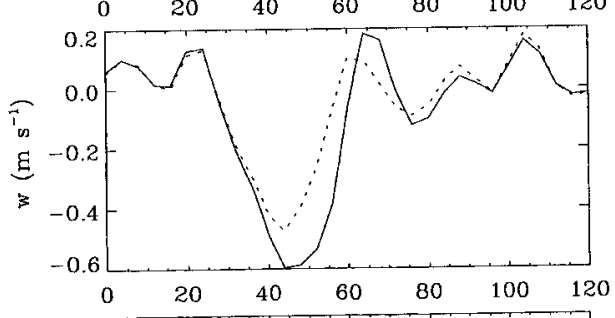

(e)

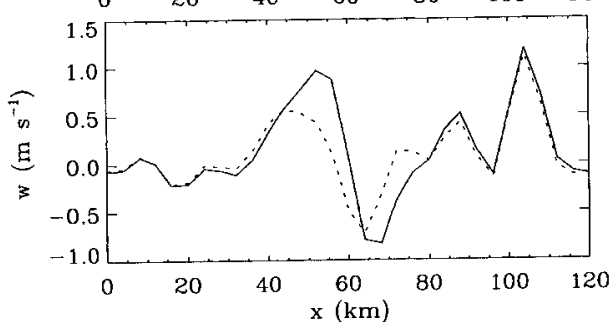

FIG. 9. Sensitivity of mountain wave generation to a change of surface friction. West-east section along $61.24^{\circ} \mathrm{N}$ at 1600 UTC. (a) and (b) Isentropes and flow in the lower troposphere for experiment $M$ with standard surface friction scheme and experiment MF with increased surface friction scheme. (c)-(e) Comparison of experiment M (solid) and MF (dotted): (c) zonal and (d) vertical velocity component in the lowest model layer, (e) as in (d) but at 6-km altitude.

Additionally, the buoyancy frequency has been calculated from the in situ temperature measurements made on the upper and lower flight leg of the ER-2 and from the 1200 UTC sonde launched at Narssarssuaq.

The values of buoyancy frequency derived from the 
in situ temperature measurements by the ER-2 and the sonde suggest a higher static stability between 18- and $21-\mathrm{km}$ altitude than the potential temperature cross section derived from the MTP data. If the vertical temperature gradient is derived from the MTP data using only the channels adjacent to the flight level a higher stability is calculated as well (Table 3 ). This suggests that the mean buoyancy frequency derived from the entire section of the MTP data from 18 to $21 \mathrm{~km}$ is too low and the stability in the simulation probably more realistic.

A closer look at the temperature retrieval from the MTP data points to a likely cause of a systematic error. Large corrections of up to $30 \mathrm{~K}$ need to be applied to the temperature retrieved at the distant levels above the aircraft to account for the transparency of the atmosphere (Gary 1989). Obviously, these corrections can result in large errors of the mean vertical temperature gradient.

However, no definitive conclusion can be drawn as the alternative calculations of the buoyancy frequency apply to slightly different altitude ranges or times. Despite the fact that most of the observations support the mean static stability in the simulations, it should be noted that the data used for the lateral boundary of the model constitute a potential source of error. Due to the low vertical resolution of the analysis data in the stratosphere $(100,70,50,30 \mathrm{hPa})$, the initial and lateral boundary conditions contain only limited information on the vertical structure. Shallow inhomogeneities in the stratosphere are not represented in the upstream conditions of the simulations. However, such shallow structures are apparent in the 1200 UTC sounding of Narssarssuaq above $18 \mathrm{~km}$, especially in the buoyancy profile (Fig. 2, Table 3). The variations of buoyancy frequency in the sounding can be due to variations in the mean conditions and variations caused by a passage through the mountain wave. Any error in the mean value of the buoyancy frequency in the simulation would affect the amplitude and phase of the simulated mountain wave.

\section{Dynamics of the stratospheric mountain wave event}

Here we further investigate the three-dimensional dynamics of the flow over the southern tip based on results from experiment HF, which is considered as the most realistic simulation. We focus on the low-level flow, the three-dimensional wave propagation, and the breaking of gravity waves.

\section{a. Flow around versus flow over orography}

The orography of Greenland is sufficiently high to decelerate and deflect the low-level flow. The Froude number of the flow at the southern tip is estimated to $\mathcal{F}=\bar{u} /\left(\bar{N} h_{0}\right) \approx 0.3$, where $h_{0}=2.2 \mathrm{~km}$ is the crest height of the ridge protruding south at $44^{\circ} \mathrm{W}$ and $\bar{u}, \bar{N}$ are vertically averaged values of wind speed and buoyancy frequency $150 \mathrm{~km}$ upstream of the southern tip. Due to the low Froude number the air impinging on the ridge at the southern tip cannot pass entirely over it. The ridge partially blocks and partially deflects the flow around it (Fig. 10a). In the vicinity of the sounding station Narssarssuaq the flow stagnates. On the meso$\alpha$ scale the low-level flow approaching Greenland at an altitude below about $1.5 \mathrm{~km}$ is meridionally deflected. At $62^{\circ} \mathrm{N}$ the flow splits into two airstreams. One turns north and the other to the south. The latter airstream follows the west coast of Greenland until it reaches the southern tip.

A shallow layer of the air impinging on the southern tip below crest height is able to pass over the tip. Figures $10 \mathrm{~b}-\mathrm{d}$ show the lower-tropospheric flow in a vertical section oriented along the flow. From the surface to an altitude of $1.5 \mathrm{~km}$ the upstream cross-ridge velocity component is less than $2 \mathrm{~m} \mathrm{~s}^{-1}$. Above there is considerable flow across the ridge. Air with a potential temperature of more than about $278 \mathrm{~K}$ is lifted sufficiently to pass over the southern tip.

The flow over the orography above the layer of stagnating and horizontally deflected air is associated with considerable vertical shear below crest height upstream of the southern tip. The 1200 UTC sounding from Narssarssuaq corroborates this simulation result. From the surface to an altitude of $1 \mathrm{~km}$, wind speeds of less than $3 \mathrm{~m} \mathrm{~s}^{-1}$ are reported. Between 1- and 2-km altitude the observed wind speed increases to $12 \mathrm{~m} \mathrm{~s}^{-1}$ (Fig. 2). In the simulation the shear is slightly weaker; a speed of $12 \mathrm{~m} \mathrm{~s}^{-1}$ is attained at about $2.5-\mathrm{km}$ altitude.

The dividing streamline height studied by Snyder et al. (1985) provides an estimate of the altitude that the transition from the flow around to the flow over the ridge occurs at. For the ridge at the southern tip with a crest height $h_{0}=2.2 \mathrm{~km}$ and a flow with Froude number $\mathcal{F}=0.3$ a dividing streamline height of $H_{s}=h_{0}(1-$ $\mathcal{F})=1.5 \mathrm{~km}$ is expected.

The $278 \mathrm{~K}$ isentrope, which approximately marks the transition from flow around the ridge to flow over it, has an altitude of about $1.8 \mathrm{~km}$ at a distance of $60 \mathrm{~km}$ upstream of the ridge (Figs. 10b,c). The simulation shows that only a shallow layer of the air below crest height passes over the ridge in agreement with the estimate of the dividing streamline height. The thickness of this layer is about $400-700 \mathrm{~m}$. The precision of this estimate is limited by the vertical resolution, which is of the same order of magnitude, and by the uncertainty about the unperturbed height of the $278-\mathrm{K}$ isentrope.

Obviously, the main source of gravity waves is the flow of the shallow layer that passes over the ridge. Thus, the horizontal scale of the excited waves is determined by the part of the orography that pierces the layer of flow that is blocked and diverted around the southern tip (Fig. 10b). The width of this part of the ridge ( $h \geq 1500 \mathrm{~m}$ ) is about $30 \mathrm{~km}$ in the direction of the flow. This is of the same order of magnitude as the 
(a)

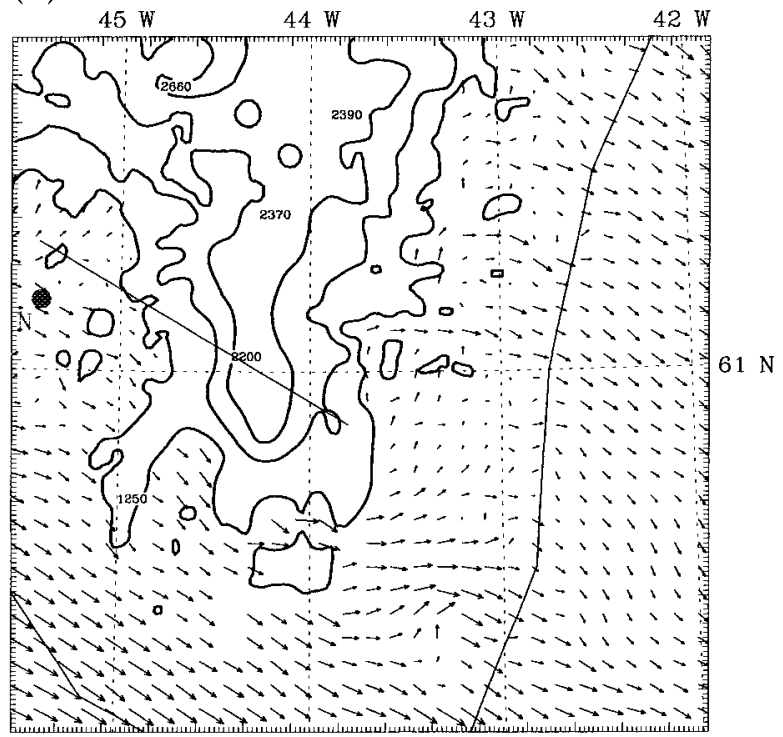

(b)

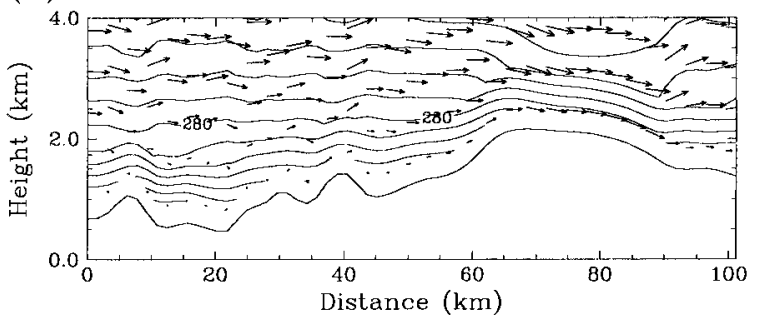

(c)

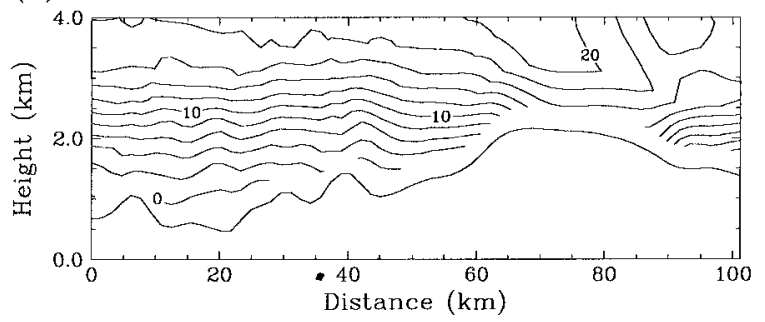

(d)

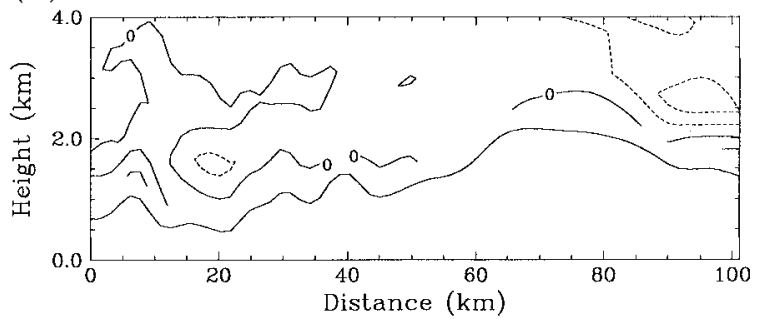

FIG. 10. Low-level flow in simulation HF at 1600 UTC. (a) Wind at $1.25-\mathrm{km}$ altitude, orography $(1000 \mathrm{~m}, 1500 \mathrm{~m}, \ldots$, heavy solid), sounding station Narssarssuaq (dot, $\mathrm{N}$ ), baseline of section shown in the other panels. (b) Isentropes and flow vectors, (c) horizontal velocity component parallel to the section (every $2 \mathrm{~m} \mathrm{~s}^{-1}$ ), (d) as in (c) but normal velocity component. dominant horizontal wavelength simulated and observed in the stratosphere.

\section{b. Wave propagation}

The flow over the ridge at the southern tip and down the eastern slope of Greenland generates a large amplitude gravity wave that propagates vertically (Fig. 11). There is evidence for two regions of wave breaking in the simulation. One is located in the lower troposphere and the other in the stratosphere above the ER-2 flight level. The wave breaking is further discussed in section $5 \mathrm{c}$. The nonlinear interactions and mixing in the tropospheric breaking region will affect the amplitude of the wave that emanates from it. Here we inspect the wave propagation above the tropospheric wave breaking into the stratosphere up to the altitude of the ER-2 flight. In this altitude interval no further wave breaking occurs and linear theory arguments can be employed to explain the dominant pattern simulated at the ER-2 flight level.

The perturbation induced by the mountain wave is illustrated by the vertical displacements of the 290- and 460-K isentropic surfaces (Fig. 12). The altitudes of the two surfaces correspond to the altitude of the tropospheric wave-breaking region and the ER-2 flight level, respectively. As in the previous section the vertical displacement of an isentropic surface is calculated as the difference in height between the surface and the inclined plane that is closest to it in model domain D4.

The main perturbation of the flow at the level of the tropospheric wave breaking is located over the upper part of the eastern slope of Greenland (Fig. 12a). The 290-K isentropic surface is displaced downward by up to $0.4 \mathrm{~km}$ over the lee slope and immediately downstream upward by up to $0.4 \mathrm{~km}$. During the vertical propagation the wave energy is spread horizontally. At the ER-2 flight level the main signature of the wave is an upward displacement of the isentropic surfaces along a north-south-oriented band. This band is situated over the upper part of the lee slope, but it extends farther south than the orography. A maximum upward displacement of $0.5 \mathrm{~km}$ is found at $44.0^{\circ} \mathrm{W}$ close to the flight track of the ER-2 (Fig. 12b).

A remarkable feature of the simulated wave pattern at an altitude of $20 \mathrm{~km}$ is that the region perturbed by the orographic gravity wave stretches at least $70 \mathrm{~km}$ farther south than the part of the slope where the wave is generated. This is associated with the dispersion of gravity waves originating from the end of a long ridge. Within linear theory of hydrostatic flow Smith (1980) shows that the transition zone from the unperturbed flow upstream to the region influenced by mountain waves is located on parabolae $x=c y^{2}$. These get wider with increasing height. Here the $x$ coordinate is directed downstream and $y$ normal to the flow. From Smith's formula $c$ is estimated to be $0.01 \mathrm{~km}^{-1}$ for an altitude of $20 \mathrm{~km}$. As the axis of the parabola points downwind, to the southeast, the southerly branch emanating from 

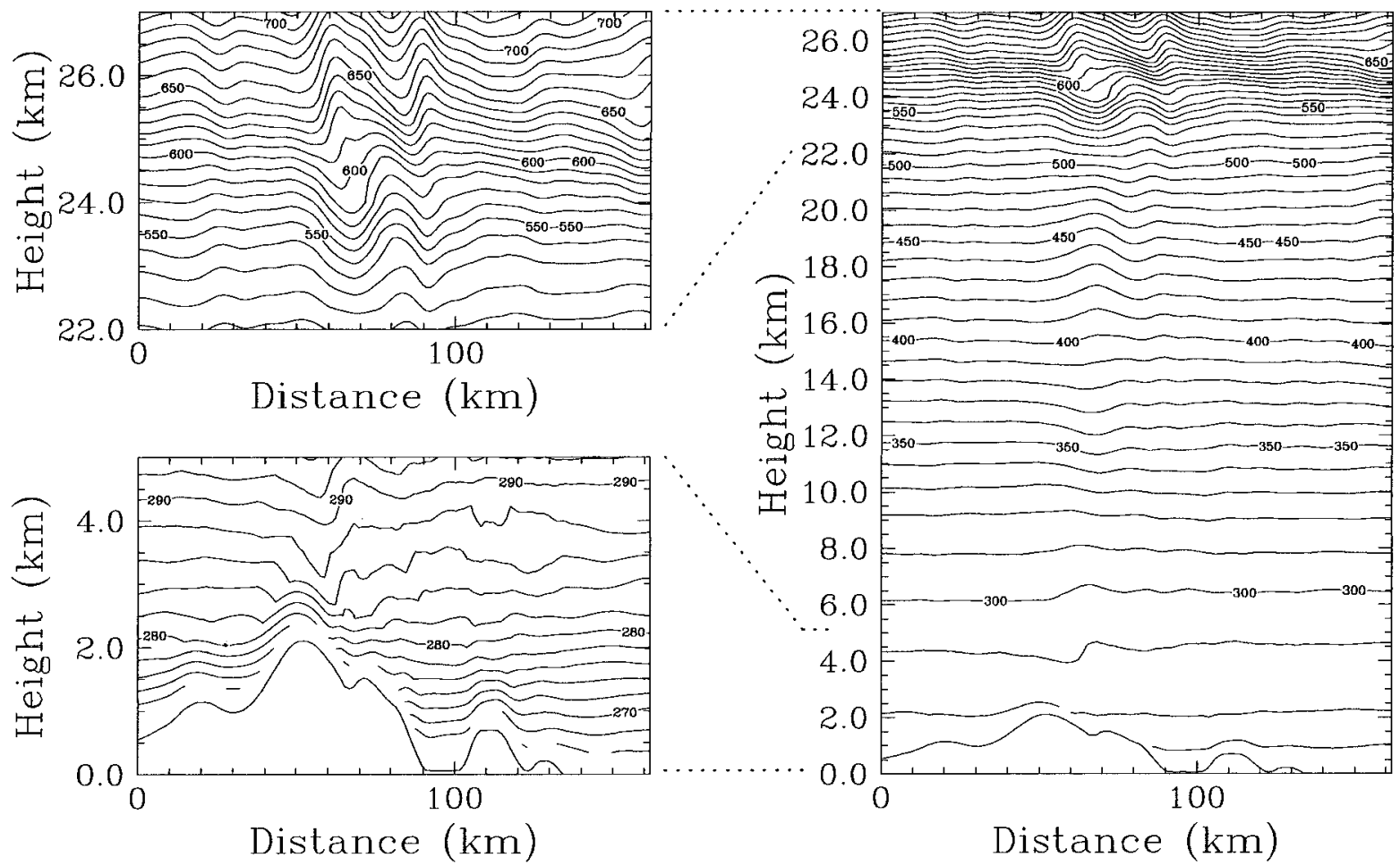

FIG. 11. (right) Wave propagation into the stratosphere and close-ups of the (bottom left) tropospheric and (top left) stratospheric wavebreaking regions. Potential temperature in west-east section along $60.85^{\circ} \mathrm{N}$ from simulation $\mathrm{HF}$ at $1600 \mathrm{UTC}$.

the tip of the ridge will be oriented approximately north to south in accordance with the leading edge of the mountain wave at $44^{\circ} \mathrm{W}$ at the ER-2 flight level.

\section{c. Wave breaking}

When the amplitude of gravity waves is so large that isentropic surfaces turn over or become vertical, instabilities set in and lead to smaller-scale motions. These motions mix momentum and entropy. In analogy to external gravity waves at a density interface this process is called wave breaking. In the real flow or numerical experiments with very high spatial resolution the vigorous smaller-scale motions can be used to identify the onset of the instabilities. However, in the simulation discussed here the instabilites are not yet resolved explicitly. The mixing of momentum and entropy is mostly parameterized. Evidence for wave breaking must rely on the resolved flow. Details of the parameterization of the subgrid-scale mixing determine whether isentropes overturn or become vertical. Therefore, an unambigous criterion for wave breaking in our simulations cannot be formulated. We decided to diagnose wave breaking where isentropes overturn or become almost vertical. An appropriate definition of almost vertical is that the slope of the isentropic surfaces is of the same order of magnitude as the aspect ratio $\Delta z / \Delta x$ of the mesh.

Using this criterion there are two regions of wave breaking over the southern tip. One in the lower tro- posphere and another in the stratosphere at an altitude of 24-25 km (Fig. 11). As there are no critical levels and the vertical shear is small in the upstream wind profile, the main cause of the stratospheric wave breaking is seen in the gradual growth of wave amplitude due to the decreasing density. From the midtroposphere to the stratospheric wave-breaking region the density decreases by a factor of 20 . Therefore, the amplitude grows by a factor of $\sqrt{20} \approx 4.5$ over this altitude range due to the decrease of density. The simulated amplitude growth is smaller (Fig. 11). We attribute this smaller growth to the increase in the buoyancy frequency and the three-dimensional dispersion of gravity waves.

The tropospheric breaking region extends from the southern tip northward over the upper part of the lee slope. It is located at altitudes between 2.5 and $5.0 \mathrm{~km}$. The regions where the breaking occurs at a potential temperature of $290 \mathrm{~K}$ can be identified in Fig. 12a. The strip of downward displacement at about $44^{\circ} \mathrm{W}$ merges with the upward displacement downstream. The cloud pattern identified on the satellite images (Fig. 3) may be a signature of the updraft associated with the tropospheric wave-breaking region as cloud and wave breaking have about the same altitude and location over the lee slope.

\section{Discussion}

In this case study we examined the propagation of orographic gravity waves into the stratosphere over the 
(a)

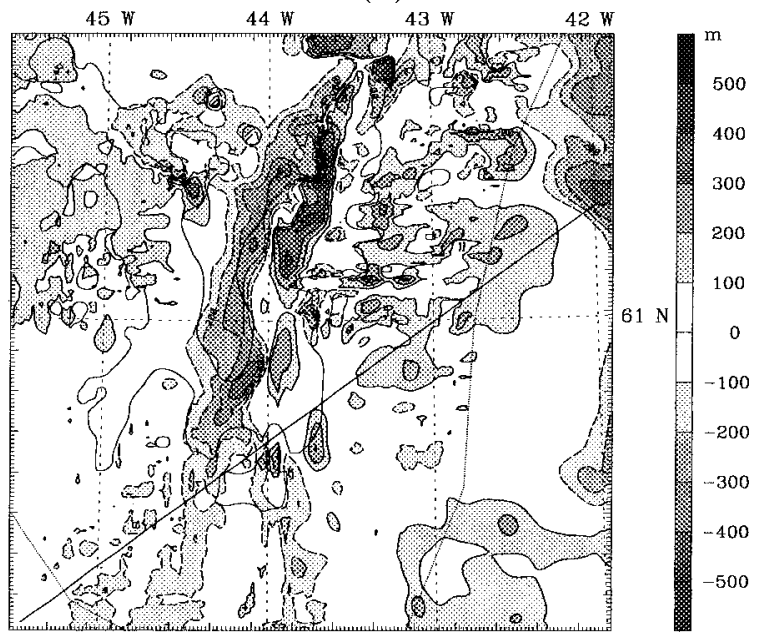

(b)

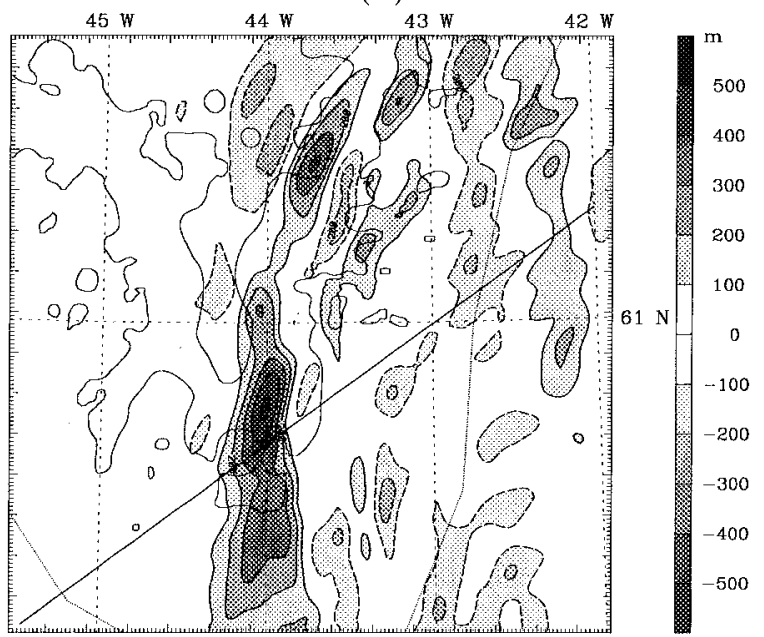

FIG. 12. Vertical displacement of isentropic surfaces (a, $\theta=290 \mathrm{~K}$ ) in the lower troposphere and (b, $\theta=460 \mathrm{~K})$ in the stratosphere at the ER-2 flight level. Upward displacement (solid contours), downward displacement (dashed contours). See text for calculation of vertical displacements. ER-2 flight track (heavy solid line); orography (1000 m, $2000 \mathrm{~m}$, thin solid contours).

southern tip of Greenland using a three-dimensional nonhydrostatic mesoscale model. The simulation results were evaluated with observations of this mountain wave event from an ER-2 flight at 20-km altitude. The sensitivity of the simulated mountain wave to the setup of the mesoscale model was studied. We focused on three aspects: resolution, surface friction, and the terrain elevation data used for the model orography.

Out of the five experiments described here, experiment HF agrees best with the observational data of the stratospheric mountain wave event. This simulation with the highest horizontal resolution $(1.3 \mathrm{~km})$ of all experiments reproduces most observed aspects of the dominant wave. Its location and horizontal scale, the amplitude of the temperature anomaly, and the vertical displacement of isentropic surfaces agree well with the observations. However, the amplitude of the strong downdraft associated with the wave is underestimated by about $50 \%$. It is expected that vertical velocity is more difficult to reproduce than other variables such as vertical displacement of isentropic surfaces or temperature as the vertical velocity field emphasizes motions on small horizontal scales.

Using fields from experiment $\mathrm{HF}$ as the best surrogate for the unknown real flow, three key dynamical processes of this stratospheric wave event have been identified. First, the low-level flow is diverted around the southern tip of Greenland and only a shallow layer of air below crest height passes over the southern tip. As a consequence, the horizontal scale of the generated gravity wave is mainly determined by the part of the orography piercing the layer of diverted flow. Thus the horizontal wavelength of the dominant mountain wave is considerably smaller than the width of the entire ridge. Second, the steepening and overturning of isentropes indicates two likely wave-breaking regions. One is lo- cated in the lower troposphere over the upper part of the eastern slope and the other in the stratosphere at an altitude of $24 \mathrm{~km}$. The wave at $20 \mathrm{~km}$, the ER-2 flight altitude, is affected by the transmission of gravity waves through the lower breaking region and the potential reflection of upward propagating gravity waves at the upper breaking region. Third, during the propagation into the stratosphere the wave energy spreads not only downstream but also normal to the flow as anticipated from group velocity arguments. This three-dimensional spread of wave energy counteracts the amplitude growth that the wave experiences due to the decrease of density with height.

The numerical experiments were set up to quantify anticipated sensitivities to resolution, surface friction, and terrain elevation data. Obviously, changes of the latter directly alter the forcing of the orographic gravity waves. The use of the more accurate terrain elevation data with $30^{\prime \prime}$ resolution in latitude and longitude yields a much better agreement of the simulated wave structure with the observed one in the stratosphere as compared to the 5' data (experiments $\mathrm{M}$ and M5). The model orography difference between these two experiments appears rather subtle compared to the massif itself. But the wave response is very sensitive to the upper part of the model orography as the wave generation occurs in a shallow layer below crest height.

The increase of surface friction from experiment $M$ to $\mathrm{MF}$ results in a reduction of the wave amplitude in the stratosphere by one-third. Qualitatively this agrees with results obtained in other studies for tropospheric mountain waves. Ólafsson and Bougeault (1997) report a reduction of the wave amplitude for idealized flow over isolated ridges and Georgelin et al. (1994) for a case study of flow over the Pyrénées when the surface friction in the numerical model is increased. From a 
comparison with aircraft observations Georgelin et al. (1994) conclude that a surface friction scheme with an effective roughness length of up to $17 \mathrm{~m}$ yields a more realistic wave response than the scheme with a constant roughness length of $0.15 \mathrm{~m}$. In our experiments the increased surface friction scheme uses a drag coefficient corresponding to a roughness length of up to $13 \mathrm{~m}$ on the slopes, whereas the standard scheme has a maximum roughness length of up to $0.6 \mathrm{~m}$ on the slopes. Although experiment $M$ agrees better with the observations than $\mathrm{MF}$, it cannot be concluded that the surface friction in $\mathrm{M}$ is more realistic. In both experiments the mountain wave is considerably damped during its propagation into the stratosphere as the analysis of the diffusion timescale shows. At the higher horizontal resolution (experiment $\mathrm{HF}$ ), the increased surface friction scheme yields a realistic wave amplitude.

For the conversion of the drag coefficient to a roughness length a neutral boundary layer has been assumed. The surface friction scheme does not depend on the stability of the boundary layer. The boundary layer over the orography is expected to be quite stable in this case. Therefore, the simulated frictional momentum transfer would correspond to even larger values of the roughness length if a formulation of surface friction was used that accounts for the stability of the boundary layer. Due to our lack of knowledge of the actual frictional momentum transfer occuring at such an inhomogeneous complex topography, we are unable to decide how realistic the surface friction in experiment $\mathrm{HF}$ is.

The sensitivity to horizontal resolution documented in the experiments showed that a fine grid is required. The demanding requirements on model resolution result from the fact that waves with horizontal wavelength less than 10 times the grid spacing are strongly affected by the horizontal diffusion of the model on the timescale of wave propagation into the stratosphere. The required high horizontal resolution is computationally expensive. Therefore, one would like to use a less diffusive model. However, a smaller constant of the horizontal hyperdiffusion is not possible with this code. Experiments with idealized low mountains diverge from linear theory results when the diffusion coefficient is reduced. Leutbecher (1998) presents a comparison with linear theory for the same amount of hyperdiffusion used in this study. The analysis of the flow in the lower troposphere in experiment HF revealed that only the upper part of the orography at the southern tip is relevant for the wave generation as the flow is diverted around the orography at lower levels. This explains why a gravity wave with relatively short horizontal wavelength is excited. The strong sensitivity of the simulated mountain wave to horizontal resolution is a consequence thereof.

The vertical resolution in the experiments is sufficient to resolve the vertical wavelength of a large part of the spectrum of orographic gravity waves. Therefore, the propagation of nonbreaking gravity waves is expected to be insensitive to an increase of vertical resolution.
However, the wave generation in the shallow layer of flow passing over the southern tip of Greenland and the wave breaking in the lower troposphere and stratosphere are expected to be more sensitive to a change of vertical resolution. Experiment MF has been repeated with 100 instead of 53 levels to quantify this suspected sensitivity. In this high vertical resolution experiment the structure of the wave is similar to that in experiments MF. The amplitude of the vertical displacement of isentropes at ER-2 flight altitude is somewhat larger than in experiment MF. It reaches $71 \%$ of the observed $0.8 \mathrm{~km}$. Thus the effect of increasing the vertical resolution is smaller than that of increasing horizontal resolution or lowering the surface friction (cf. experiments $\mathrm{HF}$ and $\mathrm{M}$ ).

This case study showed encouraging agreement of the simulated and observed mountain wave in the stratosphere using the high horizontal resolution of $1.3 \mathrm{~km}$. It also showed considerable sensitivity with respect to changing the horizontal resolution. Therefore, it seems natural to wonder whether further increasing horizontal and vertical resolution would still alter the simulated stratospheric mountain wave. The ultimate objective is to determine the resolution threshold beyond which the simulated stratospheric mountain wave is invariant to further increasing the resolution. It remains an open question where this resolution threshold is in a complex flow as the one presented. It is unclear whether a convergence of the solution can be reached with current computing resources and available numerical algorithms. It will be hard to reach convergence for a realistic case study if the global solution crucially depends on the processes in the wave-breaking regions. There energy is efficiently tranferred to smaller scales. In the present simulations the associated mixing of momentum and heat is merely parameterized by an increased diffusion. To actually resolve the relevant dynamics of the three-dimensional breakdown of the gravity wave itself a much higher resolution is required (e.g., Fritts et al. 1996). Such studies are so far limited to domains that are of the same size as the breaking region itself.

Acknowledgments. The public availability of the mesoscale model MM5 and the user support from the National Center for Atmospheric Research are greatly appreciated. Several of the contour plots have been prepared with the RIP-package from Mark Stoelinga, University of Washington, Seattle. ECMWF provided the global analyses and the NOAA-11 data were obtained from the Satellite Receiving Station of Dundee University. Hermann Mannstein, Deutsches Zentrum für Luft- und Raumfahrt, Oberpfaffenhofen, helped with the display and interpretation of the satellite images. Tassilo Kubitz, Freie Universität Berlin, provided the Narssarssuaq sounding. A discussion with Philippe Bougeault, Météo France, Toulouse, on an earlier version of this work sparked off the examination of the sensitivity to surface friction. Comments from two anonymous reviewers helped to improve the presentation. 


\section{REFERENCES}

Afanasyef, Y. D., and W. R. Peltier, 1998: The three-dimensionalization of stratified flow over two-dimensional topography. $J$. Atmos. Sci., 55, 19-39.

Bacmeister, J. T., and M. R. Schoeberl, 1989: Breakdown of vertically propagating two-dimensional gravity waves forced by orography. J. Atmos. Sci., 46, 2109-2134.

Carslaw, K. S., and Coauthors, 1998a: Increased stratospheric ozone depletion due to mountain-induced atmospheric waves. Nature, 391, 675-678.

— - and Coauthors, 1998b: Particle microphysics and chemistry in remotely observed mountain polar stratospheric clouds. J. Geophys. Res., 103, 5785-5796.

Chan, K. R., and Coauthors, 1993: A case study of the mountain lee wave event of January 6, 1992. Geophys. Res. Lett., 20, 25512554.

Clark, T. L., and W. R. Farley, 1984: Severe downslope windstorm calculations in two and three spatial dimensions using anelastic interactive grid nesting: A possible mechanism for gustiness. $J$. Atmos. Sci., 41, 329-350.

Denning, R. F., S. L. Guidero, G. S. Parks, and B. L. Gary, 1989: Instrument description of the airborne microwave temperature profiler. J. Geophys. Res., 94, 16 757-16765.

Dörnbrack, A., M. Leutbecher, H. Volkert, and M. Wirth, 1998: Mesoscale forecasts of stratospheric mountain waves. Meteor. Appl., $\mathbf{5}, 117-126$.

- — - R. Kivi, and E. Kyrö, 1999: Mountain wave induced record low stratospheric temperatures above northern Scandinavia. Tellus, 51A, 951-963.

Dudhia, J., 1993: A nonhydrostatic version of the Penn State-NCAR mesoscale model: Validation tests and simulation of an Atlantic cyclone and cold front. Mon. Wea. Rev., 121, 1493-1513.

Durran, D. R., 1992: Two-layer solutions to Long's equation for vertically propagating mountain waves: How good is linear theory? Quart. J. Roy. Meteor. Soc., 118, 415-433.

_ 1995: Do breaking mountain waves decelerate the local mean flow? J. Atmos. Sci., 52, 4010-4032.

Fritts, D. C., J. F. Garten, and O. Andreassen, 1996: Wave breaking and transition to turbulence in stratified shear flows. J. Atmos. Sci., 53, 1057-1085.

Gary, B. L., 1989: Observational results using the microwave temperature profiler during the airborne Antarctic ozone experiment. J. Geophys. Res., 94, 11 223-11 231.

Georgelin, M., E. Richard, M. Petitdidier, and A. Druilhet, 1994: Impact of subgrid-scale orography parameterization on the simulation of orographic flows. Mon. Wea. Rev., 122, 1509-1522.

Grell, G. A., J. Dudhia, and D. R. Stauffer, 1994: A description of the fifth-generation Penn-State/NCAR Mesoscale Model (MM5). NCAR Tech. Note NCAR/TN-398+IA, 120 pp.

Klemp, J. B., and D. R. Durran, 1983: An upper boundary condition permitting internal gravity wave radiation in numerical mesoscale models. Mon. Wea. Rev., 111, 430-444.

Leutbecher, M., 1998: Die Ausbreitung orographisch angeregter Schwerewellen in die Stratosphäre-Lineare Theorie, idealisierte und realitätsnahe numerische Simulation. Ph.D. dissertation, Ludwig-Maximilians-Universität München, 177 pp. [Avail- able from Deutsches Zentrum für Luft- und Raumfahrt, D-51170 Cologne, Germany.]

— mountain waves: A three-dimensional simulation using a multiscale weather prediction model. Geophys. Res. Lett., 23, 33293332.

Lilly, D. K., and P. F. Lester, 1974: Waves and turbulence in the stratosphere. J. Atmos. Sci., 31, 800-812.

Lyra, G., 1943: Theorie der stationären Leewellenströmung in freier Atmosphäre. Z. Angew. Math. Mech., 23, 1-28.

McFarlane, N. A., 1987: The effect of orographically excited gravity wave drag on the general circulation of the lower stratosphere and troposphere. J. Atmos. Sci., 44, 1775-1800.

Nastrom, G. D., and D. C. Fritts, 1992: Sources of mesoscale variability of gravity waves. Part I: Topographic excitation. J. Atmos. Sci., 49, 101-110.

Ólafsson, H., and P. Bougeault, 1997: The effect of rotation and surface friction on orographic drag. J. Atmos. Sci., 54, 193-210.

Palmer, T. N., G. J. Shutts, and R. Swinbank, 1986: Alleviation of a systematic westerly bias in general circulation and numerical weather prediction models through an orographic gravity wave drag parameterization. Quart. J. Roy. Meteor. Soc., 112, 10011039.

Pierrehumbert, R. T., and B. Wyman, 1985: Upstream effects of mesoscale mountains. J. Atmos. Sci., 42, 977-1003.

Potter, B. E., and J. R. Holton, 1995: The role of monsoon convection in the dehydration of the lower stratosphere. J. Atmos. Sci., 52, $1034-1050$.

Queney, P., 1947: Theory of perturbations in stratified currents with applications to airflow over mountain barriers. Misc. Rep. 23, Department of Meteorology, University of Chicago, Illinois, 81 pp. [Available from The University of Chicago Press, 5801 South Ellis, Chicago, IL 60637.]

Schreiner, J., C. Voigt, A. Kohlmann, F. Arnold, K. Mauersberger, and N. Larsen, 1999: Chemical analysis of polar stratospheric cloud particles. Science, 283, 968-970.

Shutts, G. J., 1992: Observations and numerical model simulation of a partially trapped lee wave over the Welsh mountains. Mon. Wea. Rev., 120, 2056-2066.

— 1998: Stationary gravity wave structure in flows with directional wind shear. Quart. J. Roy. Meteor. Soc., 124, 1421-1442.

Smith, R. B., 1980: Linear theory of stratified hydrostatic flow past an isolated mountain. Tellus, 32, 348-364.

Smolarkiewicz, P. K., and R. Rotunno, 1989: Low Froude number flow past three-dimensional obstacles. Part I: Baroclinically generated lee vortices. J. Atmos. Sci., 46, 1154-1164.

Snyder, W. H., R. S. Thompson, R. E. Eskridge, R. E. Lawson, I. P. Castro, J. T. Lee, J. C. R. Hunt, and Y. Ogawa, 1985: The structure of strongly stratified flow over hills: Dividing-streamline concept. J. Fluid Mech., 152, 249-288.

Stull, R. B., 1988: An Introduction to Boundary Layer Meteorology. Kluwer, 666 pp.

Wirth, M., and Coauthors, 1999: Model guided Lagrangian observation and simulation of mountain polar stratospheric clouds. $J$. Geophys. Res., 104, 23 971-23 981. 